NBER WORKING PAPER SERIES

\title{
MARKET REACTIONS TO TANGIBLE AND INTANGIBLE INFORMATION
}

\author{
Kent Daniel \\ Sheridan Titman \\ Working Paper 9743 \\ http://www.nber.org/papers/w9743
}

\section{NATIONAL BUREAU OF ECONOMIC RESEARCH \\ 1050 Massachusetts Avenue \\ Cambridge, MA 02138}

May 2003

We thank Nick Barberis, George Buckley, Mike Cooper, Gene Fama, Josef Lakonishook, Mitchell Petersen, Canice Prendergast, Andrei Shleifer, Walter Torous, Linda Vincent, Tuomo Vuolteenaho and seminar participants at the Federal Reserve Bank of New York, MIT, Notre Dame, Stanford, the University of Arizona, UBC, UC Berkeley, the University of Chicago and the NBER Behavioral Finance Meetings, the LSE Conference on Market Rationality, the 2001 EFMA meetings, and the Burridge Investment Conference at the University of Colorado for helpful discussions, comments and suggestions. We especially thank Kenneth French for assistance with data, and for comments and suggestions. The views expressed herein are those of the authors and not necessarily those of the National Bureau of Economic Research.

(C)2003 by Kent Daniel and Sheridan Titman. All rights reserved. Short sections of text not to exceed two paragraphs, may be quoted without explicit permission provided that full credit including $(\subset$ notice, is given to the source. 
Market Reactions to Tangible and Intangible Information

Kent Daniel and Sheridan Titman

NBER Working Paper No. 9743

May 2003

JEL No. G1

\section{$\underline{\text { ABSTRACT }}$}

We decompose stock returns into components attributable to tangible and intangible information. A firm's tangible return is the component of its return attributable to fundamental accounting-performance information, and its intangible return is the component which is orthogonal to this information. Our evidence indicates that intangible information reliably predicts future stock returns. However, in contrast to previous research, we find that tangible returns have no forecasting power. The premia associated with intangible information pose challenges for both traditional asset pricing models and models based on psychological factors.

\section{Kent Daniel}

Kellogg School of Management

Northwestern University

2001 Sheridan Road

Evanston, IL 60208

and NBER

kentd@kellogg.northwestern.edu

Sheridan Titman

McCombs School of Business

University of Texas

Austin, Texas 78712

and NBER

titman@mail.texas.edu 


\section{Introduction}

During the past decade, financial economists have puzzled over two related observations. The first is that over long horizons, future stock returns are negatively related to past stock returns. The second is that stock returns are positively related to price-scaled variables, such as the book-to-market ratio. ${ }^{1}$

DeBondt and Thaler $(1985,1987)$ were the first to document the long-horizon return reversal evidence. They argue that the evidence supports psychological theories that suggest that individuals tend to overreact to information. By looking at specific accounting based information, Lakonishok, Shleifer, and Vishny (1994, LSV) provide further support for this hypothesis. Specifically, they find that future returns are negatively related to past sales growth, suggesting that investors overreact to the information embedded in sales growth rates.

As Fama and French $(1993,1995)$ stress, since changes in fundamental performance are likely to be associated with changes in risk, this evidence is also potentially consistent with a risk-based explanation. They argue that high book-to-market and low past return firms are distressed and hence riskier, and the higher average returns earned by these firms are compensation for this risk. Fama and French (1996) provide evidence that the long-horizon return reversal effect is subsumed by the stronger book-to-market effect. In addition, they argue that both return premia result from covariation with a priced-risk factor, a proxy for which is the return of their HML portfolio, a zero investment portfolio that consists of long positions in high book-to-market stocks and short positions in low book-to-market stocks. ${ }^{2}$

While these behavioral and risk-based explanations are very different, both are based on the idea that high future stock returns are related to poor past fundamental performance. In one case, investors overreact to fundamentals, and in the other, risk is negatively related to past fundamental performance (or distress). In this paper we show that neither of these interpretations is quite right. Specifically, we show that future returns are unrelated to past fundamental performance, where fundamental performance is measured using standard accounting growth measures of firm performance.

To understand this finding, note that while there is a negative correlation between the book-to-market ratio and past accounting growth measures (i.e. high BM firms are indeed

\footnotetext{
${ }^{1}$ We review this literature in Section II.

${ }^{2}$ However, Daniel and Titman (1997) point out that the Fama and French empirical results are also consistent with mispricing-based models.
} 
generally distressed, as Fama and French (1995) and LSV document), not all high bookto-market firms are distressed. For example, a firm can become a high book-to-market firm as a result of either high earnings growth (which pushes up book), or a relatively low past return (which pushes down the market price). Thus, it is conceivable that the book-to-market effect could be generated by underreaction rather than overreaction to the information in past earnings. ${ }^{3} \quad$ For example, much of the accounting information (e.g., earnings or book value growth) of the Internet firms in the late 1990s was consistent with financial distress. However, since other information about their future growth opportunities were viewed very favorably, they had extremely low book-to-market ratios. To the extent that the subsequent low returns of Internet stocks can be characterized as resulting from previous overreaction, the culprit is overreaction to this other information, which we will call intangible information, and not to the tangible accounting information that has been discussed in the above-cited literature. ${ }^{4}$

To explore these issues in more detail, we provide a breakdown of the information that moves stock prices into two components: tangible and intangible information. ${ }^{5}$ The Oxford English Dictionary defines a tangible property or form as "That can be laid hold of or grasped by the mind, or dealt with as a fact." and intangible "... That cannot be grasped mentally." Consistent with this, we define tangible information as performance information like sales, earnings and cash flow growth, which can be extracted from the firms' accounting statements. We define intangible information as the other determinants of a stock's past return. Correspondingly, we define tangible returns as the component of returns that can be linked directly to these accounting growth numbers. Intangible returns, in contrast, presumably reflect changes in expectations about future cash flows or discount rates.

Figure 1 illustrates our calculation of tangible and intangible returns. ${ }^{6}$ Each year, we perform a cross-sectional regression of firms' past 5-year log-returns on a variety of fundamental growth measures (unanticipated book-value, earnings, cash-flow, and sales growth, or all of these). For a given firm at a given point in time, we calculate $\log \left(\hat{P}_{t}\right)-$ its expected $\log$ price at time $t$ conditional on $\log \left(P_{t-5}\right)$ and on its unanticipated funda-

\footnotetext{
${ }^{3}$ There is however, some evidence consistent with underreaction to fundamentals at shorter horizons, for example post-earnings announcement drift (see, for example Rendleman, Jones, and Latane (1982) and Bernard and Thomas (1989).

${ }^{4}$ What we are calling tangible and intangible information should not be confused with what accountants call tangible and intangible assets, which refer to assets that cannot be objectively valued.

${ }^{5}$ In Appendix B, we provide a simple model that further motivates our decomposition.

${ }^{6}$ The assumption here is that the log-price per share change is equal to the log return. In our empirical tests, we will do these calculations on a adjusted per-share basis, as described in Section A.
} 


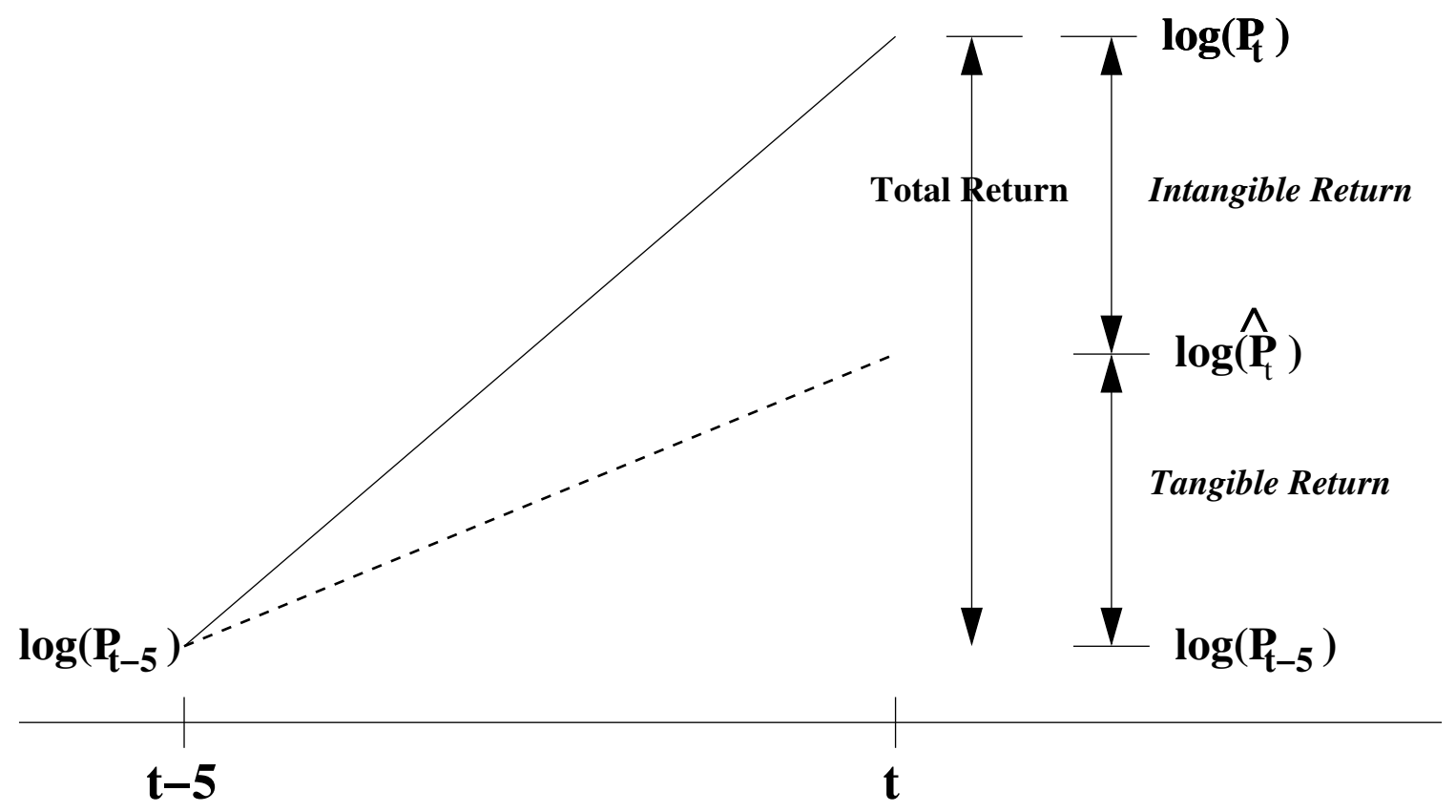

Figure 1: Graphical illustration of the breakdown of a firm's past return into tangible and intangible returns.

mental growth between $t-5$ and $t$. We define a given firm's tangible return as the fitted component of this cross-sectional regression, illustrated by the dashed line in the figure, and the intangible return as the residual. One can think of the tangible return as the past 5-year stock return that would be expected based solely on the past fundamental-growth measures. The intangible return is then the part of this past return that remains unexplained, and presumably is the result of investor response to information not contained in the accounting-growth measures we use.

Empirically, we find that we can explain a substantial fraction of the cross-section of past realized returns with these accounting-growth measures. The average $R^{2} \mathrm{~s}$ in our cross-sectional regressions range up to $60 \%$, depending on the fundamental performance measures used. This is not surprising: past stock returns, especially over a relatively long-horizon like 5 years, should be closely linked to fundamental performance. Also not surprising is that we find a strong positive relation between intangible returns and future fundamental performance measures: a firm's intangible return does, at least partially, reflect information about its future growth prospects.

What is more interesting is what we uncover about the relation of future returns to tangible and intangible information. In particular, we find no evidence of any link between past tangible information and future returns, which is in sharp contrast to previous results (e.g., those in LSV) and to the usual risk-based and behavioral interpretations of the 
reversal and book-to-market effect discussed earlier. In addition, we find a strong negative relation between past intangible returns and future returns. In other words, evidence of return reversals are generated solely by the reversal of the intangible component of returns. As we shall show, this explains why the book-to-market effect subsumes the DeBondt and Thaler (1995) reversal effect.

In addition to investigating the accounting and stock return-based measures of intangible information, we introduce what we call the composite share issuance variable. This variable measures the quantity of shares the firm issues (or repurchases) in exchange for cash or services. Thus, seasoned issues, employee stock option plans, and share-based acquisitions increase the issuance measure, while repurchases, dividends and other actions which take cash out of the firm reduce the issuance measure.

There are two rationales for introducing this variable. The first has to do with reconciling our results with the seemingly contradictory results in LSV. As we will discuss later in the paper, LSV's measure of sales growth is the firm's total sales growth, and therefore incorporates both internally and externally funded growth. As an example of the latter, a firm could double its sales by doing a stock-financed merger with a firm with equal sales. We argue that the two sources of growth are fundamentally different, and that to properly interpret the LSV results, one must separate the effects of these two sources of growth. We do so, and find that future returns are unrelated to internally-funded growth in sales, earnings, cash flow or book value. However, future returns are strongly negatively associated with share issuance. Based on this, we conclude that if this return predictability is a result of overreaction, it is not a result of investor overreaction to tangible performance information, but rather a result of underreaction to the manager's decision to issue.

In addition, our issuance variable is of interest because it is likely to capture components of intangible information that are not accounted for in our accounting-based variables. Indeed, the composite issuance variable is strongly positively correlated with our accounting-based measure of past intangible returns, suggesting that there is a common component that drives both variables. Specifically, managers tend to issue shares following the realization of favorable intangible information and repurchase shares following the realization of unfavorable intangible information. One interpretation of this is that favorable intangible returns reflect the arrival of profitable investment opportunities, perhaps as a result of decreases in the firm's discount rate, which may require external funding. An alternative interpretation is that positive intangible returns reflect mispricing, providing firms with the opportunity to improve their value by timing the equity 
market, i.e., issuing shares when they are overpriced and repurchasing shares when they are underpriced. ${ }^{7}$ Regardless, if managers have information about the magnitude of the intangible information that is not reflected in our accounting-based measures, then the composite issuance variable will capture a component of the intangible return that would not otherwise be captured.

To test whether this second measure of intangible information provides additional explanatory power we include the composite issuance variable in multiple regressions that also include accounting-based proxies for tangible and intangible information. In these multiple regressions, the composite share issuance variable is significantly negatively related to future returns, providing further evidence that stock prices perform well (poorly) subsequent to the realization of unfavorable (favorable) intangible information.

Our evidence that future returns are negatively related to past intangible returns suggests that intangible returns either contain information about mispricing, or about the future risk and discount rate of the firm's cash flows. There are several reasons why intangible returns might reflect risk. It is possible that as the expected cash flows from growth options grow - reflected by high intangible returns - their risk declines. A second possibility is that changes in risk/discount rates are uncorrelated with information about future cash flows. In this case a negative shock to a firm's discount rate would result in a high current return, one we would label as an intangible return, and would be followed by a subsequent low (expected) return, consistent with our evidence.

Of course, the implication of any such risk-based model would be that intangible returns forecast the covariance of firm returns with priced risk factors. Consequently, we examine whether return covariances behave in a way consistent with this explanation. In short, we find no support for such an explanation. Indeed, firms with high past intangible returns actually have higher market betas. However, as usual, this may very well mean that the rational expectations framework is correct, but that we have the wrong risk factors. It is possible that future tests will uncover economically plausible risk-factors which explain the average returns of these portfolios.

There are also behavioral explanations for why returns might be related to the past realization of tangible and intangible information. For example, the psychology literature

\footnotetext{
${ }^{7}$ The empirical evidence in Hovakimian, Opler, and Titman (2001) indicate that firms tend to repurchase (issue) shares when their stock prices perform poorly (well) relative to changes in their cash flows. Baker and Wurgler (2002) argue that this tendency reflects the fact that managers time the equity markets. The evidence in Loughran and Ritter (1997) and Ikenberry, Lakonishok and Vermaelen (1995) on long run performance following equity issues and repurchases is consistent with the idea that managers can in fact successfully time the equity markets.
} 
suggests that individuals react differently to information that is difficult to interpret. Specifically, individuals tend to be more overconfident in settings where more judgment is required to evaluate information, and where the feedback on the quality of this judgment is ambiguous in the short run (see, e.g., Einhorn (1980)). ${ }^{8}$ If this is the case, then we might expect investors to put too little weight on tangible information relative to intangible information. We show that this interpretation is consistent with the empirical findings in this paper.

The distinction between tangible and intangible information may also be related to the Daniel, Hirshleifer, and Subrahmanyam (1998, DHS) distinction between public and private information. Current earnings are publicly disclosed, while more ambiguous information about growth opportunities are at least partially collected (or interpreted) privately by investors. DHS argue that investors are overconfident about the precision of their private signals and, therefore, in the long run, will overreact to intangible private information and underreact to tangible public information. ${ }^{9}$

To put somewhat more structure on this behavioral explanation we provide a simple model in the appendix, in which risk neutral investor form expectations incorrectly. Consistent with the behavioral evidence cited earlier, the investor overestimates the precision of the signal he extracts from intangible information, but properly estimates the precision of the signal extracted from harder tangible information. As the model illustrates, to a large extent the implications of the behavioral model have direct analogies with the more traditional risk-based models. For example, risk premia decreasing with favorable intangible information, which is consistent with our results, have the same implications as over-reaction to intangible information. Moreover, random changes in risk premia, which can also generate our results, provides the same implications as stock prices reacting to

\footnotetext{
${ }^{8}$ There are two additional papers that we know of that find evidence consistent with this hypothesis. Daniel and Titman (1999) find that the momentum effect is stronger among growth firms than among value firms, and interpret this as resulting from the fact that more of growth firms' value arises from growth options that must be evaluated subjectively. Also, the evidence in Chan, Lakonishok, and Sougiannis (1999) suggests that the book-to-market effect is far stronger among firms with high R\&D expenditures. Daniel, Hirshleifer, and Subrahmanyam (2001) interpret this evidence as consistent with more of the value of high $\mathrm{R} \& \mathrm{D}$ firms coming from intangibles, about which investors are more overconfident. Also related is Klibanoff, Lamont, and Wizman (1999) who find evidence of overreaction to what they call "salient" information.

${ }^{9}$ The distinction between tangible and intangible information plays less of a role in the model developed by Barberis, Shleifer, and Vishny (1998, BSV), which was at least partially motivated by the LSV results. The BSV model is based on the idea that investors misinterpret the pattern of information events, like earnings announcements. Although their arguments can probably be applied to intangible as well as tangible information signals, their interpretation is presented in terms of investors overreacting to tangible information like earnings and sales.
} 
pure noise. Although we are not able to directly test our behavioral model, we view it as plausible alternative to the specific risk-based models that we do test.

\section{Related Literature}

There is now substantial evidence that individual stock returns are predictable. This evidence can be divided into three categories. First, there is evidence that past returns can be used to forecast future returns. At horizons of 3 to 12 months, excess returns exhibit positive serial correlation or momentum (Jegadeesh and Titman 1993), while at longer horizons of 3 to 5 years, there is evidence of negative serial correlation or reversal. ${ }^{10}$

In the second category, price-scaled variables, such as the earnings-to-price, dividendto-price, cash flow-to-price, the book-to-market ratio, and market-capitalization itself forecast future returns. ${ }^{11}$ The ratio that has been most studied in recent years is the book-to-market ratio. Studies find that stocks with high book-to-market ratios have historically generated much higher returns than stocks with low book-to-market ratios, and more importantly, that these returns cannot be easily explained with traditional asset pricing models. ${ }^{12}$

In the third and final category, there are a number of studies that examine the long term price reaction to specific information events. These information events can be categorized as either management decisions such as capital structure changes, dividend changes, and stock splits, or information about firm performance, such as earnings and sales figures. There is considerable evidence that investors underreact to information conveyed by management decisions. ${ }^{13}$

\footnotetext{
${ }^{10}$ See DeBondt and Thaler, $(1985,1987)$, and Chopra, Lakonishok, and Ritter (1992). In addition, at very short horizons there is evidence of negative autocorrelation in individual stock returns (Jegadeesh (1990) and Lehmann (1990)).

${ }^{11}$ For evidence on $e / p$, see Basu (1983), Jaffe, Keim, and Westerfield (1989). For $b / m$, see Stattman (1980), Rosenberg, Reid, and Lanstein (1985), DeBondt and Thaler (1987), and Fama and French (1992). For $c / p$ see Lakonishok, Shleifer, and Vishny (1994) and Chan, Hamao, and Lakonishok (1991) provide evidence on $c / p$ and other price-scaled variables in the US and Japan, respectively.

${ }^{12}$ For example, Daniel and Titman (1997) show that stock returns can be better explained by the characteristics of the firm than by the sensitivity of returns to Fama and French (1993) factors (see also Davis, Fama, and French (2000) and Daniel, Titman, and Wei (2001).) Also the Sharpe-ratios of strategies based on the size, book-to-market, and momentum characteristics are high, especially given their apparently low correlation of the returns from these strategies with important economic variables. A variant of the Hansen and Jagannathan (1991) argument shows that this is only possible in a rational asset pricing model when there is highly variable marginal utility across states (see also MacKinlay (1995) and Brennan, Chordia, and Subrahmanyam (1998).)

${ }^{13}$ The appendix of Daniel, Hirshleifer, and Subrahmanyam (1998) reviews this evidence, and provides citations to the original works.
} 
The decision to issue or repurchase shares is of course a management decision, but one that is based on past firm performance, anticipated future performance, and the firm's share price. Empirical evidence suggests that benchmark-adjusted future returns are lower following "issuance" events (i.e., decisions to exchange firm ownership for cash or services), and higher following "repurchase" events which exchange cash for firm ownership, such as repurchases and dividend increases. See, for example Loughran and Ritter (1997) (seasoned offerings), Ikenberry, Lakonishok, and Vermaelen (1995) (repurchases), Michaely, Thaler, and Womack (1995) (dividend initiations and omissions).

The existing evidence on the price reaction to information about firm performance depends on the horizon over which returns are measured. For example, there is substantial evidence of short-term underreaction to earnings surprises. However, as we note in the Introduction, Lakonishok, Shleifer, and Vishny (1994) provide evidence over longer horizons that suggests that stock prices overreact to sales and cash flow information as well as earnings.

\section{Decomposition of the Book-to-Market Ratio}

As we discussed in the Introduction, our analysis decomposes stock returns into a component that can be attributed to tangible information and a second component that can be attributed to intangible information. Specifically, the realized return from $t-5$ to $t$ (i.e., the five year period before our portfolio formation date) is expressed as:

$$
\tilde{r}(t-5, t)=E_{t-5}[\tilde{r}(t-5, t)]+\tilde{r}^{T}(t-5, t)+\tilde{r}^{I}(t-5, t) .
$$

where $E_{t-5}[\tilde{r}(t-5, t)]$ is the expected return at $t-5$, and $\tilde{r}^{T}$ and $\tilde{r}^{I}$ are the unanticipated returns resulting from (unanticipated) Tangible and Intangible information, respectively.

Our empirical work regresses returns in the current month on proxies for past realizations of tangible and intangible returns. The null hypothesis of these regressions, that current returns are unrelated to past realizations of tangible and intangible returns, is consistent with a setting where investors have rational expectations and are risk-neutral. However, if these past returns provide information about a firm's riskiness, or alternatively if investors over- or underreact to information, past tangible and intangible returns may predict current returns. In Appendix B we present a simple model that explicitly derives the regression coefficients that arise under various alternatives under which investors over or under react to information. 
If we interpret accounting growth measures as tangible information, then our distinction between tangible and intangible returns can be viewed as a distinction between that portion of a stock's return that can be explained by accounting growth measures and that portion that is unrelated to these "fundamental" performance measures. To illustrate this, consider the following decomposition:

$$
b m_{t} \equiv \log \left(\frac{\mathrm{BE}_{t}}{\mathrm{ME}_{t}}\right)=\log \left(\frac{B_{t}}{P_{t}}\right)=\underbrace{\log \left(\frac{B_{t-\tau}}{P_{t-\tau}}\right)}_{\equiv b m_{t-\tau}}+\log \left(\frac{B_{t}}{B_{t-\tau}}\right)-\log \left(\frac{P_{t}}{P_{t-\tau}}\right) .
$$

The book-to-market ratio at time $t$ is defined either as the ratio of the total bookequity $\mathrm{BE}_{t}$ to the total market equity $\mathrm{ME}_{t}$, or as the ratio of the book value per share $B_{t}$ to the market value per share (or share price) $P_{t}$. We decompose the log of the later ratio into the $\tau$-period ago log book-to-market ratio, plus the log change in its book value, minus the log change in its price.

The elements of this book-to-market decomposition are directly related to those of the tangible/intangible return decomposition given in equation (1). First, $b m_{t-\tau}$ serves as a proxy for both the firm's expected return between $t-\tau$ and $t$ and, more importantly, for the expected growth in book value over this period; empirically, high book-to-market firms have both higher future accounting growth rates and lower future returns. The log change in book value will capture both the anticipated and unanticipated growth from $t-\tau$ to $t$. The unanticipated component of this can be thought of as a proxy for the new tangible information that arrives between $t-\tau$ and $t$, while (after adjusting for splits, dividends, etc.) the log change in share price is equal to the log stock return, and will reflect all new information, tangible as well as intangible.

This decomposition is useful because it can help us understand why the log bookto-market ratio $\left(b m_{t}\right)$ tends to predict future returns. Specifically, by regressing current returns on the individual components of the decomposition, we can determine whether the power of the book-to-market ratio to forecast future returns results from a correlation of current returns with past tangible returns, intangible returns, or some long-lived component of the firm reflected in the lagged book-to-market ratio.

Before running such a regression there are some adjustments that need to be made so that the elements of the book-to-market decomposition more accurately reflect our definitions of tangible and intangible returns. A good proxy for new information (both tangible and intangible) about firm value is the total return to a dollar invested in the firm. Thus, we must first convert the change in the market value per share of a firm's 
equity to the return on its stock. If there are no splits, dividends, etc., these will be the same, but in general some adjustment must be made. The relation between the log returns and price changes are given by the expression:

$$
r(t-\tau, t) \equiv \sum_{s=t-\tau+1}^{t} \log \left(\frac{P_{s} \cdot f_{s}+D_{s}}{P_{s-1}}\right)
$$

where $f_{s}$, a price adjustment factor from $s-1$ to $s$, adjusts for splits and rights issues. $D_{s}$ is the value of all cash distributions paid between time $s-1$ and $s$, per-share owned at $s-1$, and $P_{s}$ is the per share value at time $s .{ }^{14} \mathrm{~A}$ slight manipulation of this equation shows that the log return is equal to the log price change plus a cumulative log share adjustment factor $n(t-\tau, t)$, which is equal to the (log of the) number of shares one would have at time $t$, per share held at time $t-\tau$, had one reinvested all cash distributions back into the stock.

$$
\begin{aligned}
r(t-\tau, t) & \equiv \sum_{s=t-\tau+1}^{t} \log \left(\left(\frac{P_{s}}{P_{s-1}}\right) \cdot f_{s} \cdot\left(1+\frac{D_{s}}{P_{s} \cdot f_{s}}\right)\right) \\
& =\sum_{s=t-\tau+1}^{t} \log \left(\frac{P_{s}}{P_{s-1}}\right)+\underbrace{\log \left(f_{s}\right)+\log \left(1+\frac{D_{s}}{P_{s} \cdot f_{s}}\right)}_{\equiv n_{s}} \\
& =\sum_{s=t-\tau+1}^{t} \log \left(\frac{P_{s}}{P_{s-1}}\right)+\sum_{s=t-\tau+1}^{t} n_{s} \\
& =\log \left(\frac{P_{t}}{P_{t-\tau}}\right)+n(t-\tau, t)
\end{aligned}
$$

Substituting expression (4) into equation (2) gives the current log book-to-market ratio as the sum of the lagged log book-to-market ratio and what we call the book-return, minus the log return.

$$
b m_{t}=b m_{t-\tau}+\underbrace{\log \left(\frac{B_{t}}{B_{t-\tau}}\right)+n(t-\tau, t)}_{\equiv r_{B}(t-\tau, t)}-r(t-\tau, t)
$$

$r_{B}(t-\tau, t)$, the book return between $t-\tau$ and $t$, is intuitively very much like the stock return: the log stock return is the answer to the question: If I had purchased $\$ 1$ (market

\footnotetext{
${ }^{14}$ We follow CRSP in this definition. Our $f_{s}$ is equivalent to the CRSP factor to adjust price in period, See the 2002 CRSP Data Description Guide for the CRSP US Stock Database and CRSP US Indices Database, pages 77, 84 and 156 .
} 
value) of this stock $\tau$ years ago, what would the (log of the) market value of my investment be today? The log book return instead tells you what the (log of the) book value of your shares would be today had you purchased $\$ 1$ worth of book value of this stock $\tau$ years ago. $^{15}$

If we write the current book-to-market ratio in terms of the stock return and the book return we obtain:

$$
b m_{t}=b m_{t-\tau}+r_{B}(t-\tau, t)-r(t-\tau, t)
$$

Hence, the current book-to-market ratio can be expressed as the past book-to-market ratio, plus the log book return, minus the log stock return.

In our empirical work we will investigate the relation between the variables on the RHS of this equation and future returns. Calculation of the lagged log book-to-market ratio and the log stock return are straightforward. To calculate the remaining variable, the log book return, we sum the log change in the book value per share from $t-\tau$ to $t$ and the share adjustment factor $n(t-\tau, t)$, following the definition in equation (5). ${ }^{16}$ The monthly share adjustment factor each month is calculated using the prices at the beginning and end of the period, and the return over the period (all from CRSP). From equation (3), we have that:

$$
n_{s}=r_{s}-\log \left(\frac{P_{s}}{P_{s-1}}\right) .
$$

Calculating the cumulative adjustment factor $n(t-\tau, t)$ then simply involves adding up the individual $n_{s}$ 's over the period from $t-\tau$ to $t$.

In Section IV we present estimates of regressions of returns on subsets of the variables on the right hand side of equation (6). Our goals in these regressions are to determine the relation between current returns and past tangible and intangible returns. To determine the relation between past tangible and current returns, we regress current returns on $r_{B}(t-$ $5, t)$ and $b m_{t-5}$. The estimated coefficient on the book return in this regression measures whether future returns are related to tangible information. The assumptions underlying this interpretation are that $(1) r_{B}(t-5, t)$ is not influenced by intangible information; and that (2) the lagged book-to-market ratio serves as a control for the expected book return. ${ }^{17}$

\footnotetext{
${ }^{15}$ In both the stock return and book return calculations these calculations assume no additional investment in the stock, and assume reinvestment of all payouts (such as dividends) at the stock's market value at the time the payouts were made.

${ }^{16}$ An alternative method of calculating the book return is to simply plug the current and lagged bookto-market ratios and the past return $r(t-\tau, t)$ into equation (6). In our programs, we used both methods and checked for consistency.

${ }^{17}$ Table 2 shows that the lagged book-to-market ratio and the book return are strongly negatively correlated, as we would expect.
} 
As a result, the coefficient on the book return should capture the relation between the unanticipated book return (i.e. the unanticipated tangible information between $t-5$ and $t$ ) and the current stock return. Second, we run a regression with all three elements of the decomposition as independent variables. The past book-to-market ratio and the book return are assumed to control for tangible returns as well as expected returns, implying that the coefficient on the past stock returns, in this multiple regression, reveals the relation between past intangible returns and current stock returns. A detailed derivation of the expected coefficient estimates from these regressions is given in Appendix B.2

These estimates provide insights about how the observed relation between book-tomarket ratios and returns relates to the tendency of stock prices to over- or under-react to tangible and intangible information. Using this same approach, we will estimate regressions with components of decompositions of other accounting ratios that have been shown to predict stock returns. For example, the sales to price ratio can be decomposed as,

$$
s p_{t}=s p_{t-\tau}+r_{S}(t-\tau, t)-r(t-\tau, t)
$$

where $r_{S}$, the change in sales per adjusted share, can be viewed as another proxy for the tangible return. The components of this decomposition are then used in exactly the same way as the elements of the book-to-market decomposition to estimate the effect of tangible and intangible information

Finally, we provide one additional decomposition which motivates our composite share issuance measure $\iota(t-\tau, t)$, which we define below. We construct this measure with two goals. First, as we discuss in Section V, share issuance should be an additional proxy for intangible information and, consistent with this hypothesis, we will find that our composite share issuance measure is strongly negatively related to future returns. Second, we wish to compare our results with those of LSV, who examine how stock prices react to total growth in sales rather than our sales-return, which is essentially a measure of per-share change in sales. The difference between the two measures turns out to be the share-issuance measure.

We can rewrite the equation for $r_{S}$, as given in equation (8), as

$$
r_{S}(t-\tau, t)=\underbrace{\log \left(\frac{S_{t} \cdot N_{t}}{S_{t-\tau} \cdot N_{t-\tau}}\right)}_{g_{S L S}(t-\tau, t)}-\underbrace{\left(\log \left(\frac{N_{t}}{N_{t-\tau}}\right)-n(t-\tau, t)\right)}_{\equiv \iota(t-\tau, t)}
$$

where $N_{t}$ is the total number of shares outstanding at time $t$, and $S_{t} \cdot N_{t}$ is the firm's total 
sales in year $t$. We can obtain the sales-return, $r_{S}$, either by adding the adjustment factor $n(t-\tau, t)$ to the log growth of sales-per-share (as is done in equation (5) for book return), or by subtracting off what we will call the composite share issuance measure $\iota(t-\tau, t)$ from $g_{S L S}(t-\tau, t)$ (the total sales growth) as is done in equation (9) above. ${ }^{18}$ In the former case, to get a reasonable measure of sales growth per dollar of investment, we must adjust for stock-splits, etc. The adjustment factor $n$ does this. In the later case, to adjust total sales growth, splits and stock dividends are not a concern, but share-issues, repurchases and equivalent actions must be taken into account. The composite share-issuance measure $\iota(t-\tau, t)$ does this.

Notice that, based on equations $(7)$ and $(9), \iota$ can be written as:

$$
\begin{aligned}
\iota(t-\tau, t) & =\log \left(\frac{N_{t}}{N_{t-\tau}}\right)+\log \left(\frac{P_{t}}{P_{t-\tau}}\right)-r(t-\tau, t) \\
& =\log \left(\frac{M E_{t}}{M E_{t-\tau}}\right)-r(t-\tau, t)
\end{aligned}
$$

That is, $\iota(t-\tau, t)$ is the part of the firm's market-value growth that isn't attributable to stock returns. As such, corporate actions such as splits and stock dividends will leave $\iota$ unchanged. However issuance activity, which includes actual equity issues, employee stock option plans, or any other actions which trades ownership for cash or for services (in the case of stock option plans) increases $\iota$. For example, if a firm were to issue, at the market price, a number of shares equal in value to $20 \%$ of the shares outstanding at the time, this would increase $\iota$ by $\log (1.2) \approx 0.18$. In contrast, repurchase activity such as actual share repurchases, dividends, or any other action which pays cash out of the firm decreases $\boldsymbol{\iota}$.

In the next section, we examine the extent to which the three components of a firm's book-to-market ratio and composite share issuance individually predict future returns.

\section{Empirical Results}

\section{A. The Book-to-Market Decomposition: Empirical Results}

This subsection reports estimates from Fama and MacBeth (1973) regressions of monthly returns on the three components of the book-to-market ratio, as given in equation (6).

\footnotetext{
${ }^{18}$ Notice that we can use $\iota$ to convert any "total" measure to "return" form. For example $r(t-\tau, t)=$ $\log \left(\mathrm{ME}_{t} / \mathrm{ME}_{t-\tau}\right)-\iota(t, t-\tau)$.
} 
The regressions examine a time lag, $\tau$ of five years, over which we measure the book and market returns. This corresponds to the time horizons over which there is strong existing evidence of return reversals.

\section{A.1 Data Construction}

Our regression analysis in the next subsection examines various decompositions of each firm's log fundamental-to-price ratios, where the "fundamental" measures include bookvalue, sales, cash-flow and earnings. Consistent with the previous literature, we define a firm's log book-to-market ratio in year $t\left(b m_{t}\right)$ as the log of the total book value of the firm at the end of the firms' fiscal year ending anywhere in year $t-1$ minus the log of the total market equity on the last trading day of calendar year $t-1$, as reported by CRSP. The other three ratios are defined analogously. Book value, sales, cash-flow, and earnings are calculated using COMPUSTAT annual data as described in Appendix A.

The 12 cross-sectional regressions of monthly returns from July of year $t$ through June of year $t+1$ all use the same set of right-hand-side variables. The minimum six-month lag between the end of the fiscal-year and the date at which the returns are measured is to ensure that the necessary information from the firms' annual reports is publicly available information.

The variable $b m_{t-5}$ is analogously defined as the log of the total book value of the firm at the end of the firms' fiscal year ending anywhere in year $t-6$, as reported by COMPUSTAT, minus the log of the total market equity on the last trading day of calendar year $t-6$, as reported by CRSP. It is simply $b m_{t}$ lagged 5 years. $r(t-5, t)$ is the cumulative log return on the stock from the last trading day of calendar year $t-6$ to the last trading day of calendar year $t-1$ and $r_{B}(t-5, t)$ is the log book return, over the same time period, constructed as discussed in Section III. Finally, $r_{m o m}$ is the stock's 5-month cumulative $\log$ return from the last trading day of calendar year $t-1$, to the last trading day of May of year $t$. We do not include the return in June of year $t$ because of concerns about bid-ask bounce.

To be included in any of our regressions for returns from July of year $t$ to June of year $t+1$, we impose the requirement that a firm have a valid price on CRSP at the end of June of year $t$ and as of December of year $t-1$. We also require that book value for the firm be available on COMPUSTAT for the firm's fiscal year ending in year $t$. For most of our empirical analysis here, where we utilize past five-year returns and book returns, we also require that the book value for the firm be available on COMPUSTAT for the firm's 
fiscal year ending in year $t-6$, that the firm have a valid price on CRSP at the end of December of year $t-6$, and that the return on the firm over the period from December of year $t-6$ to December of year $t-1$ be available. We also exclude all firms with prices that fall below five dollars per share as of the last trading day of June of year $t$. This is because of concerns about bid-ask bounce and nontrading among very low price stocks. Finally, consistent with Fama and French (1993), we exclude all firms with negative book values in either year $t-1$ or year $t-6$, though negative values at intermediate dates do not result in exclusion. When we do our analysis with alternative fundamental measures in Section IV.B, we require that those measures (earnings, cash flow, or sales) be positive as well. ${ }^{19}$

\section{A.2 Data Summary}

Table 2 shows the average cross-sectional correlation coefficients between the variables we consider. ${ }^{20}$ Some interesting patterns emerge here. First, $b m_{t}$ and $b m_{t-5}$ are highly correlated, indicating that firms' book-to-market ratios are highly persistent. Second, $b m_{t-5}$ is highly negatively correlated with $r_{B}$, which indicates that low book-to-market or growth firms generally have higher profitability (in the form of book returns) per share in the future. ${ }^{21}$ Third the univariate correlation between $b m_{t}$ and $r(t-5, t)$ is negative and strong - that is high BM firms are indeed low past return firms. But, the correlation between $b m_{t}$ and $r_{B}(t-5, t)$ is weak and statistically insignificant, despite the fact that the correlation between $r(t-5, t)$ and $r_{B}(t-5, t)$ is strongly positive. This indicates that, on average, high $b m$ firms have experienced low past stock returns, rather than having experienced high book returns. Consistent with this, a multivariate regression of $b m_{t}$ on $r_{B}(t-5, t)$ and $r(t-5, t)$ (not shown) generates strongly statistically significant positive

\footnotetext{
${ }^{19}$ Needless to say, there are a lot of firms that are not included in our analysis because we need to measure book-to-market ratios in fiscal year $t-6$. Hence, our sample does not include firms that are younger than 5.5 years. However, since the returns we calculate are associated with implementable portfolio strategies, there are no biases associated with our selection criteria.

${ }^{20}$ The t-statistics presented below each correlation coefficient are the based on the time-series of crosssectional correlation coefficients, as in the Fama-MacBeth regressions. Because of the serial-correlation in the time-series of correlation coefficient, we use a Newey-West procedure with 6 lags to calculate standard errors.

${ }^{21}$ This positive correlation is consistent with other findings, such as Fama and French (1995) and Vuolteenaho (2002). In particular Vuolteenaho uses a VAR to decompose a firm's stock return into two components: shocks to expected cash flows and shocks to expected returns (or discount rates). He finds that the typical firm's returns are mainly a result of news about cash flows, as opposed to future expected returns. He also finds that shocks to expected-returns and shocks to future cash flows are positively correlated, meaning that, ex-ante firms which are expected to have high future cash flow growth will also have high future expected returns.
} 
and negative coefficients, respectively. Firms that have experienced past earnings growth that is not associated with increased stock returns generally have higher book-to-market ratios, as would be expected.

\section{B. Fama-MacBeth Regression Results - Book-to-Market Decomposition}

Table 3 presents the results from a set of Fama-MacBeth regressions of stock returns on various components of the book-to-market decomposition. Regression 1, a simple regression of returns on the log book-to-market ratio, shows that the book-to-market effect is strong in our sample, which is consistent with the existing literature. Regressions 2 through 8 decompose $b m_{t}$ into its components as specified in equation (6).

Regression 2 indicates that $b m_{t-5}$ can still forecast future returns. This evidence is consistent with the persistence of the book-to-market ratio seen in Table 2 . The ability of the 5-year lagged book-to-market ratio to forecast future returns is consistent with either bm capturing some permanent firm characteristic which could be associated either with actual or perceived risk, or with long-term mispricing. For example, firms with intangible assets like patents and brand names which have persistently low book-to-market ratios may have unique return patterns that are associated with their characteristics. It is also possible that the risk or mispricing effects captured by $b m$ are temporary, but of longer duration than 5 years. We do not attempt to discriminate between these two hypotheses. ${ }^{22}$

The next set of univariate regressions allow us to gauge the extent to which returns are related to past realizations of tangible and intangible information. Specifically, Regression 3 shows that the book return, on its own, does not reliably forecast future returns. When we include $b m_{t-5}$ in Regression 6, which acts as a control for the expected book return over $t-5$ to $t$, the relation between book returns and future stock returns is even weaker. This evidence is consistent with the observation that over a five year period, investors react appropriately to information about accumulated earnings. However, consistent with existing evidence, we find, in Regression 4, evidence consistent with long-term reversal. ${ }^{23}$ Regression 5 shows that a firm's composite share issuance is strongly negatively associated with its future returns, something we will discuss more in Section V,

Regressions 6-8 are multiple regressions, which include the lagged book-to-market

\footnotetext{
${ }^{22}$ However, the evidence in Chan, Lakonishok, and Sougiannis (1999) suggests that high R\&D firms don't earn consistently lower returns than firms with low or no R\&D expenditures.

${ }^{23}$ We find a particularly strong long-term reversal effect, because there is a minimum six month gap between the period over which $r(t-5, t)$ is calculated, and the returns we are forecasting. The sixmonth momentum effect, which we eliminate with this experimental design, reduces the reversal effect as calculated in DeBondt and Thaler (1985) (see Asness (1995)).
} 
ratio, the book return, and the past returns. Note that the coefficient on past returns in Regressions 7 and 8 are just slightly more negative and significant than in Regression 4, while in contrast the coefficient on book return is now positive and significant, and the coefficient on the lagged book-to-market ratio is somewhat more positive than in the univariate regressions. These observations are the same whether we control for issuance or not. The results of these regressions, in combination with the univariate regressions, are consistent with the model predictions discussed in Section III when there is overreaction to intangible information (or equivalently when positive intangible information reflects decreased risk), but no over- nor underreaction to tangible information.

\section{Calculating the Intangible Return}

The regressions reported in Table 3 find no significant relation between past tangible and future returns (Regressions 3 and 5), but a significant negative relation between past intangible returns and future returns (Regressions 7 and 8). As discussed in Section B.3, an alternative way to estimate the model is to first orthogonalize the past return with respect to the lagged fundamental price ratio and the fundamental return. In other words, we would like to calculate the portion of the stock returns that cannot be explained by fundamental accounting variables. We do this by first performing cross-sectional regressions at each time, and defining the residual from this regression as the intangible return. So, for example, to calculate the book-value based intangible return, we run the cross-sectional regression:

$$
r(t-5,5)=\gamma_{0}+\gamma_{B M} \cdot b m_{t-5}+\gamma_{B} \cdot r_{B}(t-5,5)+\tilde{u}
$$

and define the intangible return as the regression residual:

$$
r^{I(B)}(t-5, t) \equiv \tilde{u}
$$

Table 4 shows the results of running the Fama-MacBeth regressions with both the intangible (orthogonalized) returns, and with the non-orthogonalized returns. Regressions 1 and 2 in this Table are identical to Regressions 6 and 7 in Table 3. These are included for comparison with Regression 3. In Regression 3, we include the lagged book-to-market ratio, the book return, and the intangible return which is the past return orthogonalized with respect to $b m_{t-5}$ and $r_{B}(t-5,5)$ as described above. In Regression 3, the coefficients and t-statistics on $b m_{t-5}$ and $r_{B}(t-5,5)$ are identical to those in Regression 1: this must be the case since $r^{I(B)}$ is orthogonalized to these two variables each year. Also given 
our orthogonalization procedure, the coefficient and t-statistic on $r^{I(B)}$ in Regression 3 is identical to those on $r(t-5, t)$ in Regression 2 .

The results in Regression 3 and in Table 3 reveal no reliable relation between future and past book returns, but a strongly significant relation between future returns and past intangible returns. To test the robustness of this hypothesis, we estimate similar regressions using other types of tangible information. Specifically, to be consistent with the earlier work of Lakonishok, Shleifer, and Vishny (1994), we examine sales, cash flow, and earnings. Our definitions of these variables follow LSV's; earnings are measured before extraordinary items, and cash flow is defined as earnings plus depreciation.

In Regressions 4, 7 and 10 we redo Regression 1 from Table 3, only using the lagged $\log$ sales-to-price ratio, cash flow-to-price ratio, and earnings-to-price ratio. ${ }^{24}$ These variables forecast future returns about as well as the book-to-market ratio. We then break down these fundamental-to-price ratios into the components, based on the decompositions equivalent to that in equation (2). The evidence in Regressions 6, 9 and 12 are consistent with the book return measure: the insignificant coefficients on the fundamental-return variables are insignificant and small relative to the coefficients and t-statistics on the past intangible returns in the same regressions. ${ }^{25}$

Regression 13 in Table 4 regresses future returns on the past tangible and intangible returns, where these are calculated using yearly cross-sectional multiple regressions of past returns on all eight lagged fundamental-to-price ratios and fundamental-return measures, that is:

$$
\begin{aligned}
r_{i}(t-5, t)= & \alpha+\beta_{1} b m_{i, t-5}+\beta_{2} s p_{i, t-5}+\beta_{3} c p_{i, t-5}+\beta_{4} e p_{i, t-5} \\
& +\beta_{5} r_{i}^{B}(t-5, t)+\beta_{6} r_{i}^{S L S}(t-5, t)+\beta_{7} r_{i}^{C F}(t-5, t)+\beta_{8} r_{i}^{E R N}(t-5, t)+\epsilon_{i}
\end{aligned}
$$

Specifically, in each year, the past return for each firm is broken up into three parts: an expected return/growth component, and unanticipated tangible and intangible return components. Our proxy for the unanticipated tangible return for firm $i$ is:

$$
r_{i}^{T(T o t)}(t-5, t) \equiv \hat{\beta}_{5} r_{i}^{B}(t-5, t)+\hat{\beta}_{6} r_{i}^{S L S}(t-5, t)+\hat{\beta}_{7} r_{i}^{C F}(t-5, t)+\hat{\beta}_{8} r_{i}^{E R N}(t-5, t)
$$

\footnotetext{
${ }^{24}$ We follow convention in using the terminology "price" for these three ratios, and "market" for the book-to-market ratio. "Market" has the same meaning as "price."

${ }^{25}$ The one coefficient that is close to being statistically significant here is that on $r_{S}$ in Regression 6 . However, note that the coefficient is positive rather than negative, as would expected if there is simple overreaction to past sales growth.
} 
By construction, our tangible return measure is orthoganalized with respect to $b m_{i, t-5}$, $s p_{i, t-5}, c p_{i, t-5}$, and $e p_{i, t-5}$. Assuming our specification is reasonably accurate - meaning that these price-scaled variables at $t-5$ capture expected growth, and that this relation is relatively constant across firms - our tangible return measure should measure the unanticipated changes in measured firm performance over the period from $t-5$ to $t$. Our proxy for the firm's intangible return $\left(r_{i}^{I(T o t)}(t-5, t)\right)$ is defined as the residual of this regression. The findings from Regression 13, which regresses future returns on the past tangible and intangible returns that are calculated in this manner, suggests that a firm's tangible return is not associated with future returns, but the intangible returns are strongly and significantly negatively associated with future returns.

In the last column of this Table, we also report the time-series averages of the $R^{2} \mathrm{~s}$ for the annual cross-sectional regressions of past returns on the lagged fundamental price ratios and fundamental-growth measures. These $R^{2}$ s range from $21.3 \%$ in the sales regression, to almost $60 \%$ in the total regression. In summary, the cross-sectional regressions can explain a substantial fraction of the cross-section of realized returns with these accountinggrowth measures. Again, the interesting thing here is not the high $R^{2}$ s, but the strong link between the unexplained component of the past return (the intangible component) and future returns, and the lack of such a relation for the tangible component.

\section{A Time Horizon Robustness Check}

This section examines the possibility that there is over or underreaction to tangible information over shorter horizons that we fail to pick up in the previous regressions. ${ }^{26}$ To examine this possibility, we reestimate the regressions in Table 4, only now breaking up the past fundamental returns into the components from $t-5$ to $t-3$, and from $t-3$ to $t$. Since we are doing everything in logs, the sum of these two components is the return from $t-5$ to $t$. These regressions, reported in Table 5 , show that, for each of our four basic measures of fundamental growth, both the $(t-5, t-3)$ and the $(t-3, t)$ components of fundamental-growth are unrelated to future returns. ${ }^{27}$

In Regressions 3, 5, 7, and 9 in this Table, we report the results of performing the Fama-MacBeth regressions with the tangible and intangible components of the past firm

\footnotetext{
${ }^{26}$ For example, we know that there is post-earnings announcement drift a horizons of about a year. It is possible that there is long-horizon overreaction to fundamental growth, but this is masked by the post-earnings announcement drift in our 5-year tests.

${ }^{27}$ The coefficient on $r_{S L S}(t-5, t-3)$ actually is statistically significant here $(t=2.15)$, but the coefficient is positive rather than negative, suggesting that if anything there is underreaction to lagged sales-growth at this horizon.
} 
returns. The calculations of these components is identical to what was done in Section IV.B, except that we now define the tangible return for book $\left(r^{T\left(B^{*}\right)}\right)$, for example, as the fitted component of the regression of $r(t-5,5)$ onto $b m_{t-5}, r_{B}(t-5, t-3)$ and $r_{B}(t-3, t)$. Again, these results are consistent with the hypothesis that current returns are orthogonal to past tangible returns.

\section{E. Seasonal Effects}

Both the DeBondt and Thaler (1985) reversal effect and the book-to-market effect have strong January seasonals. Given this, we expect the results presented in the previous subsections to also differ between January and non-January months.

Tables 6 and 7 present the regressions from Tables 3 and 4, estimated separately for January and non-January returns. Regressions $A$ in the two tables shows the simple reversal effect in and out of January. Consistent with other studies, we find that the reversal effect is very strong in January - the coefficient is about a factor of 25 larger than for the non-January regression - and is statistically insignificant outside of January. Also consistent with earlier work, Regression 1 in the first panel of the each of two tables shows that the $b m$ effect is stronger in January - the coefficient on $b m_{t}$ is a factor of 10 higher - but is still significant in the non-January months. The findings are about the same for the other fundamental-price ratios.

One striking thing in Table 6 is that the January coefficients in the univariate regressions on the book, sales, cashflow, and earnings returns (the regressions numbered (3)) are all significantly negative. In other words, in the month of January, there is evidence that firms that have experienced high book returns, earnings growth, or sales growth, tend to have low returns. This evidence is consistent with tax loss selling that depresses the stock returns of past winners, regardless of whether their past returns were generated because of favorable tangible or intangible information. However, offsetting this is the fact that outside of January, the equivalent coefficients are all positive, and significant at a $5 \%$ level for the sales-return and cash-flow return measures. The February-December regression results are shown in Table 7 . As a result there is no significant evidence of overor underreaction to accounting growth across the year. In addition, it should be noted that the sign on the accounting growth variables are all positive in the multiple regressions, which is consistent with the hypothesis that January reversals due to fundamental returns occur only because of the correlation between fundamental and stock returns, and that in January as well as other months, intangible returns reverse more strongly than 
tangible returns.

\section{F. Other Robustness Checks}

In this subsection we summarize the results of a variety of additional tests which we used to examine the robustness of our conclusions. An appendix detailing the results of these robustness tests is available on request from the authors.

\section{F.1 Firm Size}

We first examined whether our results are consistent across firm size. Here we classify a firm as "large" if its market capitalization is greater that that of the median NYSE firm. ${ }^{28}$

We ran our Fama and MacBeth (1973) tests for subsamples of large and small firms. The results are fully consistent with our full sample results: for both subsamples, both past intangible returns and composite share issuance forecast future the cross-section of future returns, but past tangible returns do not.

We also ran the time-series tests of the value-weighted orthogonalized portfolios of Section VI.B for subsamples of large and small capitalization stocks. Consistent with our full sample results, the composite-share-issuance based portfolio returns cannot be explained by either the CAPM or the Fama and French (1993) 3-factor model. The intangible return portfolio returns are inconsistent with the CAPM for either large or small firms, but not inconsistent the 3-factor model.

Finally, we examined whether there was a significant difference in the relation between any of these variables and future returns across firm size. Our tests find no statistically significant difference between the Fama and MacBeth (1973) coefficients on past tangible returns, intangible returns, or on composite-issuance across small and large firms. These results all hold whether we calculate tangible returns with respect to book-, earnings-, sales-, or cashflow-returns.

\section{F.2 Time Subperiod Analysis}

We also examined whether the results hold in two non-overlapping subsamples of time. The first subperiod examined was 1968:07-1985:06 (204 Months), and the second was 1985:07-2001:12 (198 Months).

\footnotetext{
${ }^{28}$ We perform this classification as of the end of June of each year, and the classification is maintained through the end of June of the subsequent year.
} 
With one exception the Fama-MacBeth tests for the subperiods are fully consistent with the full-sample results: past tangible returns don't forecast future returns at a statistically significant level, and past intangible returns and past composite-issuance both do forecast future returns. This is true whether we calculate tangible and intangible returns using sales, cash flow, or earnings,or book, with the one exception that the relation between past intangible returns and future returns is insignificant when we use book.

\section{F.3 Asymmetry Tests}

We also investigate whether there is any asymmetry in the intangible-return or composite share issuance effects. Specifically, we examine whether past positive and negative intangible (and tangible) returns forecast future returns differently. If the predictability we observe arises because of mispricing, and short sale restrictions make it costly for arbitrageurs to eliminate overpricing, such asymmetries might result. However, we found no evidence of any statistically significant asymmetries for intangible returns. Interestingly, when tangible returns are calculated using cash flow measures, there is marginally significant evidence of a difference for tangible returns, but the relation is slightly stronger for negative past tangible returns, which goes against the short-sale constraints hypothesis.

\section{Share Issuance and Future Returns}

In this Section we examine the relation between the composite share issuance measure introduced in Section III and future returns. As we mentioned in the introduction, we have two rationales for this. First, in Subsection V.A we use this measure to reconcile our findings with the LSV findings that suggest that stock prices overreact to past sales growth. In addition, as we discuss in Subsection V.A below, the share-issuance variable provides an additional measure of intangible information.

To understand this, recall that past evidence (e.g., Hovakimian, Opler, and Titman (2001)) indicates that firms are more likely to issue equity and less likely to repurchase shares following periods when their stock prices perform well relative to their earnings. Table 8 shows that this is also the case in our sample. ${ }^{29}$ Specifically, we find that firms tend to issue (repurchase) shares following favorable (unfavorable) intangible information; that is when past returns have been high relative to past book returns.

\footnotetext{
${ }^{29}$ The dependent variable in these regressions is somewhat different than what was examined in the prior literature. The prior literature examines issuance, repurchases and dividends separately. In contrast, we are examining a single variable that captures the effect of all three sources of changes in equity capital.
} 
Of course, the tangible information that managers observe is much more precise than the accounting information we use in this study, so they also have better information on intangible information. As a result, the issuance/repurchase choices provide independent information about intangible information; hence, if investors underreact to intangible information, or alternatively, if intangible information is related to risk, these choices should forecast future returns. However, their issuance choices will not be a perfect proxy for the intangible information - other factors will also influence a firm's issuance decision (whether they issue or repurchase, and how much). This suggests that both our intangible return proxies and the composite issuance chosen by the manager should forecast future returns.

To test this possibility, in Table 9 we add $\iota(t-5, t)$ to our earlier regressions of returns on accounting-returns and various measures of intangible return. These regression estimates show that $\iota(t-5, t)$ and intangible returns are both significant when the two variables are included in the same regression, suggesting that these variables indeed have independent effects on returns.

As with our other evidence, the are several possible interpretations of this negative issuance-return relation. One is that managers understand that the market overreacts to intangible information (and underreacts to the decision to issue). Hence managers issue opportunistically, timing their issues and repurchases to take advantage of mispricing. Alternatively, managers may simply issue when growth options/investment opportunities look favorable; that is following a period of high intangible returns. If investors either overreact to the intangible information conveyed by the issuance choice, or alternatively, the issuance choice is related to the firm's risk, then future returns will be related to the issuance choice in much the same way that returns are related to our accounting-based measures of intangible information.

\section{A. The Relation of our Results to the Findings of LSV}

As discussed earlier, Lakonishok, Shleifer, and Vishny (1994, LSV) provide empirical results which they argue support the hypothesis that investors overreact to tangible information. Specifically, LSV find a strong and significant negative relation between a firm's past sales growth and its future stock returns. This result, which contrasts with the findings reported in Table 4, is puzzling since our sales return measure is similar to the sales growth measure used by LSV. In this section we reexamine the LSV findings and explain why our conclusions are so different. 
We show here that the difference arises because LSV's tests use a firm's total sales growth, as opposed to our sales return measure which examines growth per dollar invested. This distinction is important since total sales growth can result either from increasing the scale of operations (e.g., by acquiring another firm) or from increasing the efficiency or productivity of the firm's existing assets.

Mathematically, this is straightforward. Equation (9) showed that:

$$
g_{S L S}(t-\tau, t)=r_{S L S}(t-\tau, t)+\iota(t-\tau, t)
$$

That is, high total log sales growth $g_{S L S}$ can either result from high past sales return (a high $r_{S L S}$ ), or from scale increases associated with high past share issuance. This means that the negative relation between $g_{S L S}$ and future returns that LSV uncover could be caused by a negative relation between $r_{S L S}$ and future stock returns, but could also be an artifact of a negative relation between past issuance activity and future stock returns, which is consistent with the previous literature (see Section II) and with our results (see Regressions 5 and 8 in Table 3).

This subsection shows that the strong negative relation between $g_{S L S}$ and future returns is indeed attributable to the negative relation between equity issuance and future returns. Specifically, we show that after controlling for equity issuance there is no relation between total sales growth and future returns.

Only a small fraction of firms have high issuance activity $(\boldsymbol{\iota})$, and as we show it is these high $\iota$ firms that are largely responsible for the observed sales growth-return relation. Specifically, we find that after excluding the $10 \%$ of the firms with the greatest composite share issuance, but not necessarily with the highest total sales growth, there is no longer any relationship between total sales growth and future returns. Thus, the LSV results appear to be attributable not to overreaction to any sort of fundamental growth, but rather to underreaction to information about management choices that affects inflows and outflows of equity capital. Because management's decision to issue does not generally reflect favorable tangible information — indeed, Table 8 shows that firms are more likely to issue following poor fundamental performance — managers are presumably issuing following good intangible returns, consistent with our results in Table 8.

Regressions 2 and 3 of Table 10 report the results of Fama-MacBeth regressions that verify that the LSV results continue to hold using our methodology and sample. In Regression 2, the coefficient on $g_{S L S}$, the total sales growth, is significantly negative. Regression 3 reveals, consistent with LSV's findings, that in a multiple regression the 
coefficients on the cash flow to price ratio $(c p)$ and $g_{S L S}$ are both significant, and the coefficient of $g_{S L S}$ remains about the same as in the corresponding univariate regression. This is not surprising given that the average cross-sectional correlation between $c p$ and $g_{S L S}$ is close to zero $(-0.079, t=-1.18)$. Thus $c p$ and $g_{S L S}$ have separate explanatory power for future returns.

However, Regression 4 shows that if instead of using $g_{S L S}$ as an independent variable in the regression, we use our sales return measure $r_{S L S}$ we get a coefficient that is quite different and is statistically insignificant. This difference is striking and somewhat surprising since the average cross-sectional correlation between $g_{S L S}$ and $r_{S L S}$ is quite high ( $\rho=0.764, t=11.1)$. Again, the difference is due to the fact that $g_{S L S}$ is defined as the log change in the total sales of the firm, while $r_{S L S}(t-\tau, t)$ is adjusted for new issues, repurchases, etc.. The difference between the two measures is composite share issuance $\iota(t-\tau, t)$, as defined in equation $(9)$.

As discussed in Section III, $\iota$ will be positive if a firm has issued equity and negative if a firm has repurchased shares or pays dividends. ${ }^{30}$ Consistent with this, Regressions 6-8 in Table 10 illustrate that there is a strong negative relation between $\iota(t-5, t)$ and future returns, and that, after controlling for $\iota$, growth in sales has no significant explanatory power for future returns.

Note that this evidence does not support the theory that investors overreact to all sales growth, whether caused by scale increases or not. If this were the case, then we would find that these two components of sales growth would both forecast future returns. Instead, we find that once we control for share issuance there is no relation between past sales growth and future returns.

As a robustness check, we eliminate the $10 \%$ of firms with the highest $\iota$ measure (i.e., with the highest amount of share issuance) from our sample and re-estimate Regressions 1, 2 and 3 of Panel A with this truncated sample. These are presented as Regressions 12, 13 and 14 in Panel B of Table 10. Regression 12 shows that this truncation has very little effect on the ability of the $c p$ measure to forecast future returns. However, Regressions 13 and 14 reveal that, among the remaining $90 \%$ of the firms without strong issuance, there is no remaining statistically significant relation between $g_{S L S}$ and future returns, even if we control for the cash flow-to-price ratio.

Interestingly, regression 15 shows that eliminating the extreme $\iota$ firms weakens but doesn't eliminate the relation between $\iota$ and future returns - there is still enough variation

\footnotetext{
${ }^{30} \iota$ will also be affected by employee stock option plans, and any other actions which trade ownership for cash or for services (in the case of stock option plans).
} 
in $\iota$ in this truncated sample so that $\iota$ is still a statistically reliable predictor of future returns. Regressions 16 and 17 show that controlling for $\iota$ further weakens the relation between $g_{S L S}$ and future returns in the truncated sample, but the change is not statistically significant. ${ }^{31}$

\section{Risk and Intangible Returns}

Cross-sectional predictability can result either from risk differences between securities, or from changes in mispricing. In this section we investigate the possibility that these return patterns arise because tangible and intangible information realizations are associated with different levels of risk. We do this by first examining how past tangible and intangible information realizations correlate with changes in systematic and total risk. We then examine the risk-return relation of portfolio strategies based on intangible returns.

\section{A. Changes in Risk Measures and Intangible Returns}

Up to this point we have shown that a zero-investment portfolio which buys low past intangible stocks and shorts high past intangible return stocks earns high future returns. As we mentioned earlier, this finding is consistent with rational expectations only if high past intangible return stocks realize high returns in bad states of the world and low returns in good states. That is, if the covariance risk of stocks is inversely related to the arrival of intangible information.

There are several theoretical reasons why a stock's risk should be correlated with its past tangible and intangible returns. For example, Berk, Green, and Naik (1999) propose a model in which risk changes are consistent with the empirically observed value premium. In their model, the beta of a firm endowed with a growth opportunity decreases when favorable information is revealed. Intuitively, the growth option moves further in the money, so its elasticity with respect to the payoff value declines.

However, other effects can reverse this relationship. For example, both the number of

\footnotetext{
${ }^{31}$ One could argue that even our sales return measure doesn't fully control for scale changes via security issuance: specifically, if a firm doubles the scale of its operations via a debt issue, it could double both total sales and sales return. Thus, to the extent that future returns are related to past debt-issuance, this could induce an apparent relationship between past sales-return and future returns when none truly exists. To examine this possibility, we ran the above regressions but included a control for log-total-asset growth over the five years prior to portfolio formation. Sales-return remains significant in this regression, but interestingly the total-asset growth coefficient is also negative and significant, suggesting that higher debt as well as equity issuance over the preceding five years forecasts lower future stock returns.
} 
growth opportunities and their values, relative to the value of assets in place, are likely to increase with favorable information about asset values. Since growth opportunities are essentially options, they have higher betas than assets in place, which suggests that favorable information about the value and number of a firm's growth opportunities relative to its assets in place will result in an increase in its beta. The increased tilt toward growth opportunities is likely to be especially important when firms experience high intangible returns.

Thus, depending on which effect dominates, covariance risk can either increase or decrease following positive intangible returns. To examine this issue empirically, we estimate a set of Fama-McBeth regressions that allow us to measure how tangible and intangible information affect risk. We do this by examining two proxies for risk: the firms' market betas and their total variance.

We first examine the market beta. Table 11 presents the results of a set of FamaMacBeth regressions in which the dependent variable is the firms' beta with respect to the CRSP value weighted index in the two years following portfolio formation. The independent variables are the fundamental-to-price ratios, fundamental returns, and tangible and intangible returns we have previously used to forecast returns. Because we are interested in how risk changes with new tangible and intangible information, we also include as a control $\hat{\beta}_{t-5}$, which is the lagged beta measured over the 24 months from $t-6$ to $t-4$.

These regressions reveal that, for all accounting growth measures except sales, and for the total tangible and intangible returns, the relation between the past intangible return and beta is significantly different from zero, but the coefficients are positive rather than negative. This evidence, which is consistent with intangible returns being associated with the addition of new growth opportunities, is inconsistent with the theory that the higher returns associated with stocks with low intangible returns is compensation for systematic risk.

CAPM beta is of course an imperfect measure of risk. Thus, in Table 12 we examine whether the coefficient relating past tangible and intangible returns to total firm return standard deviation are consistent with a risk-based story. This table presents the results of Fama-MacBeth regressions of the firms' monthly return standard deviation in the two years following portfolio formation on the lagged standard deviation and on our measures of past tangible and intangible returns. These regressions show that, in almost all cases, the coefficient relating the change in the firms' return standard deviation to the past 
intangible return is positive; the exception is once again the sales-based calculation.

These results should be interpreted cautiously: the beta and standard-deviation series in the regressions are highly autocorrelated and while we use Newey-West standard errors to determine the t-statistics, these standard errors are correct asymptotically but may not be valid for the short time we examine series here. However, our results for past intangible returns in the next subsection confirm the general findings of this section.

\section{B. The Risk-Adjusted Returns of the Fama-MacBeth Portfolio Strategies}

In previous sections we have shown Fama-MacBeth regressions that suggest that the returns to trading on past intangible return issuance might be large. In this section we investigate whether such returns are likely to be achievable, and whether the CAPM or the Fama and French (1993) three-factor model can explain the mean returns of these portfolio strategies.

One way to interpret the time-series of coefficients in a set of Fama and MacBeth regressions is as a set of returns to zero-investment portfolios with weights at each time given by the rows of the matrix

$$
\mathbf{W}_{t}=\left(\mathbf{X}_{\mathbf{t}}^{\prime} \mathbf{X}_{\mathbf{t}}\right)^{-1} \mathbf{X}_{\mathbf{t}}^{\prime}
$$

where the matrix $\mathbf{X}_{t}$ is the set of independent variables from the cross-sectional regression at time $t$.

Portfolios with these weights can be constructed, and if one were able to trade at the prices reported by CRSP, the average returns of these portfolios would equal the coefficients reported in the preceding tables. However, these portfolios are effectively equal-weighted and thus require monthly rebalancing. This means that bid-ask bounce, illiquidity, and transaction costs might make the actual returns from such a strategy unachievable, especially for low market-capitalization portfolios.

In this section we consider value-weighted versions of these coefficient portfolios. The weight on asset $i$ at time $t$ in this portfolio is:

$$
\mathbf{w}_{t}^{V W}=\frac{\left(\mathbf{w}_{t}^{E W}\right)^{+} \cdot \mathbf{M E}_{t}}{\mathrm{ME}_{t}^{+}}+\frac{\left(\mathbf{w}_{t}^{E W}\right)^{-} \cdot \mathbf{M E}_{t}}{\mathrm{ME}_{t}^{-}}
$$

where $\mathbf{w}_{t}^{E W}$ is the appropriate row of $\mathbf{W}_{t}$ from above, $\left(\mathbf{w}_{t}^{E W}\right)^{+}$is a vector whose elements equal $\mathbf{w}_{t}^{E W}$ when this is positive, and otherwise are zero, and $\mathbf{M} \mathbf{E}_{t}$ is the vector of firm market-equity values. Finally $\mathrm{ME}_{t}^{+}$and $\mathrm{ME}_{t}^{-}$denote the sum of the market-caps of the 
firms whose elements in $\mathbf{w}_{t}^{E W}$ are positive and negative, respectively.

Constructing the weights in this way yields some nice properties. First, notice that the sum over the positive weights is +1 , and the sum over the negative weights is -1 , so the zero investment portfolio returns we report will be as conventionally defined (i.e., as the profit from going long $\$ 1$ and short $\$ 1$.). Second since our vector of RHS variables $\mathbf{X}_{t}$ only changes once per year on July 1, the returns we report will be buy-and-hold portfolio returns which are rebalanced once per year, each July 1. Finally, while this weighting scheme does not produce exact value-weighting, it does ensure that small market cap stocks should generally have portfolios weights roughly proportional to their market capitalizations. These last two properties, along with the fact that we exclude all stocks with a end-of-June price less than $\$ 5$, should mean that frictions in trading these stocks are minimized.

Table 13 presents the results of time series regressions for three zero investment portfolios with weights corresponding to three FM regression coefficients. The portfolio evaluated in Panel A has weights corresponding to the coefficient on $r^{I(B)}$ in Table 4, regression 3 ; Panel B uses the $\iota(t-5, t)$ coefficient in univariate cross-sectional regressions as in Table 9, regression $\mathrm{A}$; and Panel $\mathrm{C}$ uses the weights corresponding to the $\boldsymbol{\iota}(t-5, t)$ coefficient in the multivariate cross-sectional regressions with $b m_{t-5}, r_{B}(t-5, t), r^{I(B)}$ as additional RHS variables (as in Table 9, regression 3). That is, these weights are orthogonalized to past tangible and intangible returns.

In rows 1, 4 and 7 of Table 13 we report the mean returns and associated t-statistics for each of the three portfolios. In rows 2,5 and 8 we report the results of a time series regression:

$$
r_{p, t}=\alpha+\beta_{M k t}\left(R_{m, t}-R_{f, t}\right)+\epsilon_{t}
$$

Consistent with the results reported in the previous subsection, the coefficient on the excess market return is $0.177(t=4.73)$ : the high-intangible return firms (which experience low future returns) actually have a higher beta than the low-intangible return firms. Here, the risk story goes the wrong way. In this test, we also obtain an alpha of -0.44 $(t=-2.53)$, so we reject the CAPM-null hypothesis that $\alpha=0$.

To assess whether the return of this zero investment portfolio is consistent with the Fama and French 3-factor model one can run a time-series regression with the three FF factors as independent variables:

$$
r_{p, t}=\alpha+\beta_{M k t} \cdot\left(R_{m, t}-R_{f, t}\right)+\beta_{S M B} \cdot \mathrm{SMB}_{t}+\beta_{H M L} \cdot \mathrm{HML}_{t}+\epsilon_{t}
$$


For the intangible-return based zero investment portfolio, we get a strongly significant negative coefficient of about -1 on $\operatorname{HML}(t=-32.18)$, a negative and significant coefficient on SMB $(t=-2.53)$. Thus, we find that we can reject the CAPM, but cannot reject the FF 3 -factor model.

Panels $\mathrm{B}$ and $\mathrm{C}$ report the results of equivalent regressions for our value-weighted coefficient portfolio corresponding to the issuance variable. Here we find that the intercepts are all negative. Furthermore, we can reject the hypothesis that the SMB and HML factors explain the average returns of these portfolios at a high level of statistical significance.

\section{Conclusions}

The information responsible for stock price movements can be decomposed into two components. First, a firm's share price moves in response to new information about its current or past fundamental performance, i.e. to accounting information. Since this information is relatively concrete, we have referred to it as tangible information, and the associated return as the tangible return. The second component of the stock's return, which is by definition orthogonal to the first, is referred to as the intangible return. The intangible return presumably reflects intangible information about the firm's future cash flows, or about its risk.

We find that this decomposition is quite useful for helping us think about empirical regularities that have previously been discussed in the literature. For example, previous explanations of the reversal effect and the book-to-market effect have focused on the idea that stock returns are negatively related to past fundamental performance. These explanations include risk-based explanations which posit that risk premia are associated with past realizations of fundamental performance - for example that high book-to-market firms are "distressed" in some fundamental sense, and enjoy high risk premia for this reason. There are also behavioral explanations which posit that investors overreact to the poor earnings performance of high book-to-market firms.

Our empirical evidence is inconsistent with both explanations. Specifically, we find no significant cross-sectional relation between our past performance measures and future stock returns. Rather, we find that the book-to-market and reversal effects arise because future returns are cross-sectionally related to past realizations of intangible information, i.e., to that component of past returns that cannot be explained by the tangible informa- 
tion about fundamental performance.

The fact that we see intangible return reversals and not tangible return reversals is consistent with several other results in the literature. For example, Fama and French (1996) show that the DeBondt and Thaler (1985) reversal effect is subsumed by the bookto-market effect. We show that this is because only intangible returns reverse, and the book-to-market ratio is a good proxy for past intangible returns. In addition, there is no return reversal outside of January, while the book-to-market effect is present in all months. Consistent with this, we show that intangible return reversals occur even outside of January.

In addition, we investigate the relation between a firm's composite issuance and its future stock returns. There are at least two reasons why the composite issuance measure is likely to be related to the realization of intangible information. The first is that managers are likely to issue equity to fund growth opportunities and the second is that managers are more likely to issue equity subsequent to a decline in the perceived cost of equity. In both cases, the equity issue is triggered by information that we classify as intangible. Empirically, we find that composite issuance is strongly negatively related to future returns, even after controlling for past intangible returns. This evidence is consistent with a negative relation between the past realization of intangible information and future returns.

The predictive power of our composite issuance variable explains the discrepancy between our results and those of Lakonishok, Shleifer, and Vishny (1994, LSV). LSV present evidence that investors overreact to past sales growth rates. We show that the difference between the LSV sales growth variable and ours is that we measure growth on a per-dollarinvested basis, while LSV measure the overall firm's total sales growth. Mathematically, total $(\log )$ sales growth is equal to our measure plus composite share-issuance. Thus, firms which issue shares, undertake share-based acquisitions, or compensate their employees with stock options may have large total sales growth, but not a high sales-return. We show that only firms which grow via share issuance experience negative future returns.

There are plausible risk-based models that are consistent with the idea that risk and expected returns increase following negative realizations of intangible information. However, our preliminary analysis fails to support these models. Specifically, we find that high past intangible returns and past issuance firms have a higher CAPM beta, which is inconsistent with the lower future returns of these firms. The Fama and French (1993) three-factor model explains the abnormal future returns associated with our direct mea- 
sure of past intangible returns (because book-to-market is a good proxy for a firm's past intangible return), but fails to explain the returns associated with share issuance. It is possible that future rational-expectations models may explain our results, but such an explanation will have to show how stock returns covary with priced risk-factors in a way that makes the risk (and expected returns) decline upon the realization of good intangible information, decline when firms issue equity, and be relatively unrelated to the realization of tangible information.

Behavioral theories may offer another avenue for explaining these results. There is substantial evidence from the psychology literature that individuals are overconfident about their abilities, and as a result, tend to overestimate the quality of information signals they generate about security values. The psychology literature also suggests that the degree to which individuals are overconfident depends on the situation. In particular, individuals tend to be more overconfident about their ability to evaluate information that is relatively vague, i.e., information that we have classified as intangible. As a result, there is likely to be more evidence of overreaction to intangible information, which is consistent with our finding that favorable intangible information about a stock is followed by lower than average subsequent returns.

Up to this point, we have defined intangible information by what it is not; it is information that is orthogonal to the tangible information that appears on the firm's accounting statements. An interesting avenue of future research would be to identify sources of intangible information that leads to overreaction. We have conjectured that this is information that is related to firms' growth opportunities. In particular, it may be the case that investors overestimate the precision of relatively nebulous information about future growth opportunities, and as a result, tend to overreact to the information. Unfortunately, testing this possibility is likely to be difficult since, almost by definition, it is difficult to identify and characterize this nebulous information.

Alternatively, it is possible that our results arise because of price changes that are essentially self-generated. For example, it is plausible that small movements in stock prices, generated by relatively minor liquidity events, can snowball into major price moves if the original price move attracts the interest of momentum investors and analysts who develop "stories" to explain the price move (see, e.g., DeLong, Shleifer, Summers, and Waldmann (1990)). ${ }^{32}$ Such a scenario can be viewed as overreaction, if one classifies

\footnotetext{
${ }^{32}$ DeLong, Shleifer, Summers, and Waldmann (1990) remark that Soros' trading strategies around the conglomerate boom appear similar to positive feedback trading strategies of this sort:

The truly informed investment strategy in this case, says Soros, was not to sell short in
} 
reacting to nothing as overreacting. It is also possible that this "noise" is generated by changes in perceptions about risk. While this is a possibility, our results suggest that these changes in risk perceptions, if they do exist, are either irrational or are related to elements of risk that are quite different than traditional risk measures.

anticipation of the eventual collapse of conglomerate shares (for that would not happen until 1970) but instead to buy in anticipation of further buying by uninformed investors. The initial price rise in conglomerate stocks, caused in part by purchases by speculators like Soros, stimulated the appetites of uninformed investors since it created a trend of increasing prices and allowed conglomerates to report earnings increases through acquisitions. [our italics] 


\section{References}

Asness, Clifford S., 1995, The power of past stock returns to explain future stock returns, Working paper, University of Chicago.

Barberis, Nicholas, Andrei Shleifer, and Robert Vishny, 1998, A model of investor sentiment, Journal of Financial Economics 49, 307-343.

Basu, S., 1983, The relationship between earnings yield, market value, and return for NYSE common stocks: Further evidence, Journal of Financial Economics 12, 126-156.

Berk, Jonathan, Richard C. Green, and Vasant Naik, 1999, Optimal investment, growth options, and security returns, Journal of Finance 54, 1553 - 1607.

Bernard, Victor L., and Jacob K. Thomas, 1989, Post-earnings-announcement drift: Delayed price response or risk premium?, Journal of Accounting Research, Supplement 27, $1-48$.

Brennan, Michael, Tarun Chordia, and Avanidhar Subrahmanyam, 1998, Alternative factor specifications, security characteristics and the cross-section of expected stock returns, Journal of Financial Economics 49, 345-373.

Chan, Louis K.C., Yasushi Hamao, and Josef Lakonishok, 1991, Fundamental and stock returns in japan, Journal of Finance 46, 1739-1764.

Chan, Louis K.C., Josef Lakonishok, and Theodore Sougiannis, 1999, The stock market valuation of research and development expenditures, NBER Working Paper \#7223, July.

Chopra, Navin, Josef Lakonishok, and Jay R. Ritter, 1992, Measuring abnormal performance: Do stocks overreact?, Journal of Financial Economics 31, 235-268.

Daniel, Kent D., David Hirshleifer, and Avanidhar Subrahmanyam, 1998, Investor psychology and security market under- and over-reactions, Journal of Finance 53, 18391886.

— , 2001, Overconfidence, arbitrage, and equilibrium asset pricing, Journal of Finance 56, 921-965.

Daniel, Kent D., and Sheridan Titman, 1997, Evidence on the characteristics of crosssectional variation in common stock returns, Journal of Finance 52, 1-33.

— 1999, Market efficiency in an irrational world, Financial Analysts' Journal 55, $28-40$.

— , and John Wei, 2001, Cross-sectional variation in common stock returns in Japan, Journal of Finance.

Davis, James, Eugene F. Fama, and Kenneth R. French, 2000, Characteristics, covariances, and average returns: 1929-1997, Journal of Finance 55, 389-406. 
DeBondt, Werner F. M., and Richard H. Thaler, 1985, Does the stock market overreact?, Journal of Finance 40, 793-808.

— , 1987, Further evidence on investor overreaction and stock market seasonality, Journal of Finance 42, 557-581.

— , 1995, Financial decision-making in markets and firms: A behavioral perspective, in Robert A. Jarrow, Voijslav Maksimovic, and William T. Ziemba, ed.: Finance, Handbooks in Operations Research and Management Science, vol. 9 . chap. 13, pp. 385-410 (North Holland: Amsterdam).

DeLong, J. Bradford, Andrei Shleifer, Lawrence Summers, and Robert J. Waldmann, 1990, Positive feedback investment strategies and destabilizing rational speculation, Journal of Finance 45, 375-395.

Einhorn, Hillel J., 1980, Overconfidence in judgment, New Directions for Methodology of Social and Behavioral Science 4, 1-16.

Fama, Eugene F., and Kenneth R. French, 1992, The cross-section of expected stock returns, Journal of Finance 47, 427-465.

— 1993, Common risk factors in the returns on stocks and bonds, Journal of Financial Economics 33, 3-56.

— 1995, Size and book-to-market factors in earnings and returns, Journal of Finance 50, 131-156.

— 1996 , Multifactor explanations of asset pricing anomalies, Journal of Finance $51,55-84$.

Fama, Eugene F., and James MacBeth, 1973, Risk, return and equilibrium: Empirical tests, Journal of Political Economy 81, 607-636.

Hansen, Lars P., and Ravi Jagannathan, 1991, Implications of security market data for models of dynamic economies, Journal of Political Economy 99, 225-262.

Hovakimian, Armen, Tim Opler, and Sheridan Titman, 2001, The debt-equity choice, Journal of Financial and Quantitative Analysis 36, 1-24.

Ikenberry, David, Josef Lakonishok, and Theo Vermaelen, 1995, Market underreaction to open market share repurchases, Journal of Financial Economics 39, 181-208.

Jaffe, Jeffrey, Donald B. Keim, and Randolph Westerfield, 1989, Earnings yields, market values, and stock returns, Journal of Finance 44, 135-148.

Jegadeesh, Narasimhan, 1990, Evidence of predictable behavior of security returns, Journal of Finance 45, 881-898.

— , and Sheridan Titman, 1993, Returns to buying winners and selling losers: Implications for stock market efficiency, Journal of Finance 48, 65-91. 
Klibanoff, Peter, Owen Lamont, and Thierry A. Wizman, 1999, Investor reaction to salient news in closed-end country funds, Journal of Finance 53, 673-699.

Lakonishok, Josef, Andrei Shleifer, and Robert W. Vishny, 1994, Contrarian investment, extrapolation and risk, Journal of Finance 49, 1541-1578.

Lehmann, Bruce N., 1990, Fads, martingales, and market efficiency, Quarterly Journal of Economics 105, 1-28.

Loughran, Tim, and Jay Ritter, 1997, The operating performance of firms conducting seasoned equity offerings, The Journal of Finance 52, 1823-1850.

MacKinlay, A. Craig, 1995, Multifactor models do not explain deviations from the CAPM, Journal of Financial Economics 38, 3-28.

Michaely, Roni, Richard H. Thaler, and Kent L. Womack, 1995, Price reactions to dividend initiations and omissions: Overreaction or drift?, Journal of Finance 50, 573-608.

Rendleman, Richard J., Charles P. Jones, and Henry A. Latane, 1982, Empirical anomalies based on unexpected earnings and the importance of risk adjustment, Journal of Financial Economics 10, 269-287.

Rosenberg, Barr, Kenneth Reid, and Ronald Lanstein, 1985, Persuasive evidence of market inefficiency, Journal of Portfolio Management 11, 9-17.

Stattman, Dennis, 1980, Book values and stock returns, The Chicago MBA: A Journal of Selected Papers 4, 25-45.

Vuolteenaho, Tuomo, 2002, What drives firm level stock returns?, Journal of Finance 57, 233-264. 


\section{Appendix}

\section{A. Data Construction}

We use CRSP data for stock prices and returns. We use the merged COMPUSTAT annual data (supplied by CRSP) for all accounting information, and for the number of shares. To merge the CRSP and COMPUSTAT data, we use CRSPLink, as updated by Ken French.

To get shareholders' equity, we use, if it is not missing, Stockholders' equity (item 216). It it is missing, we use Total Common Equity (item 60) plus Preferred stock Par Value (item 130) if both of these are present. Otherwise, we use Total Assets (item 6) minus Total Liabilities (item 181), if both are present. If none of these give us a valid shareholders' equity measure, we treat shareholders' equity as missing for this firm year.

To get book equity, we subtract from shareholders' equity the preferred stock value, where we use use redemption value (item 56), liquidating value (item 10), or carrying value (item 130), in that order, as available. If all of the redemption, liquidating, or par value are missing from COMPUSTAT, then we treat the book-equity value as missing for that year. Finally, if not missing, we add in balance sheet deferred taxes (item 35) to this book-equity value, and subtract off the FASB106 adjustment (item 330).

Our earnings measure is income before extraordinary items (item 18), and our sales measure is the COMPUSTAT sales (item 12). These two definitions are consistent with those of Lakonishok, Shleifer, and Vishny (1994). Our cash-flow measure is income before extraordinary items minus the share of depreciation that can be allocated to (afterinterest) income, plus any deferred taxes, that is:

$$
\mathrm{CF}=\mathrm{INC}+\mathrm{DEPR} \times\left(\frac{\mathrm{ME}}{\text { Assets }-\mathrm{BE}+\mathrm{ME}}\right)+\mathrm{DFTX}
$$

where INC is income before extraordinary items, DEPR is depreciation from COMPUSTAT (item 14), Assets is total assets (item 6), DFTX is deferred taxes (item 50), and BE and ME are book- and market-equity, as defined above.

\section{B. Market Reactions to Different Types of Information}

This section develops a simple model that provides more explicit intuition for linking our empirical results to specific behavioral biases. The model describes three sources of stock price movements. These include accounting-based information about the firm's current profitability (tangible information); other information about the firm's future growth opportunities (intangible information); and pure noise. To keep it simple, there are three dates, 0, 1 and 2, a single risk-neutral investor, and a risk-free rate of zero.

Given these assumptions, price changes and returns would not be forecastable were all investors rational. However, in our model investors misinterpret new information and as a result make expectational errors. The model captures three kinds of errors:

1. Over- or Underreaction to Tangible Information: Investors may not correctly incorporate information contained in past accounting growth rates in forming their 
estimates of the future cash flows that will accrue to shareholders. In our empirical tests, we investigate whether investors over- or underreact to the information in earnings, cash flow, sales, or growth rates. Given the linear specification of our model Over- or Underreaction to past growth rates is equivalent to over- or underextrapolating these growth rates.

2. Over- or Underreaction to Intangible Information: Intangible information is news about future cash flows which is not reflected in current accounting-based growth numbers. Investors may over- or underreact to intangible information, perhaps because they over- or underestimate the precision of this information.

3. Pure Noise: Overreaction means that investors move prices too much in response to information about future cash flows. Alternatively, we classify stock movements as pure noise if they are uncorrelated with future cash flows. One interpretation of this comes from microstructure theory: if investors overestimate the extent to which their counterparts are informed, they will overreact to purely liquidity motivated trades. Alternatively, noise trades can represent an extreme form of overconfidence, in which investors believe that they have valuable signals about future cash flows, but in reality their signals are unrelated to future cash flows.

An alternative interpretation of what we call over- and underreaction to information and noise can arise in a model with rational risk averse investors who sometimes perceive changes in risk or experience changes in risk preferences. For example, holding expected cash flows constant, if an industrial sector becomes riskier, stock prices will initially decline (because of the increased required rate of return) and will then be expected to increase because of the increased risk premium. Moreover, changes in risk or risk preferences may also change in response to either tangible or intangible information in ways that generate return patterns that are indistinguishable from over or underreaction to these sources of information, as discussed in Section VI.A.

\section{B.1. The Model}

The following provides the timing of the various information and cash flow realizations along with a brief description of the structure of the model. A summary of the model variables are given in Table 1.

\section{Book Values and Cash Flows:}

1. At date 0 , the firm is endowed with assets with value $B_{0}$, which we denote as the initial book value of the firm's assets. We assume that the assets do not physically depreciate over time. At times 1 and 2, the firm's cash flows are $\tilde{\theta}_{1}$ and $\tilde{\theta}_{2}$. Each period, the book value grows by the amount of the cash flow.

2. At date 2 the firm is liquidated and all proceeds are paid to shareholders. Investors are risk-neutral and the risk-free rate is zero, so the price equals the expected book value at time 2 . 
Table 1: A Summary of the Model Variables

\begin{tabular}{|l||c|c|c|}
\hline & $t=0$ & $t=1$ & $t=2$ \\
\hline \hline Cash Flows $\left(\theta_{t}\right):$ & - & $\tilde{\theta}_{1}=\bar{\theta}+\tilde{\epsilon}_{1}$ & $\tilde{\theta}_{2}=\bar{\theta}+\rho \tilde{\epsilon}_{1}+\tilde{\epsilon}_{2}$ \\
Intangible Signal: & - & $\tilde{s}\left(=\tilde{\epsilon}_{2}-\tilde{u}\right)$ & - \\
Price "Noise": & - & $\tilde{e}$ & - \\
\hline \hline$B_{t}$ & $B_{0}$ & $B_{0}+\tilde{\theta}_{1}\left(=B_{0}+\bar{\theta}+\tilde{\epsilon}_{1}\right)$ & $B_{1}+\tilde{\theta}_{2}$ \\
$\left.E_{t}^{R}\left[\tilde{B}_{2}\right]\right)$ & $B_{0}+2 \bar{\theta}$ & $B_{1}+\rho \tilde{\epsilon}_{1}+\tilde{s}+\tilde{e}$ & $B_{2}$ \\
$M_{t}\left(=E_{t}^{C}\left[\tilde{B}_{2}\right]\right)$ & $B_{0}+2 \bar{\theta}$ & $B_{1}+\rho^{E} \tilde{\epsilon}_{1}+(1+\omega) \tilde{s}+\tilde{e}$ & $B_{2}$ \\
$(B-M)_{t}$ & $-2 \bar{\theta}$ & $-\left(\bar{\theta}+\rho^{E} \tilde{\epsilon}_{1}+(1+\omega) \tilde{s}+\tilde{e}\right)$ & 0 \\
\hline$r_{t-1, t}^{B}$ & - & $\tilde{\theta}_{1}\left(=\bar{\theta}+\tilde{\epsilon}_{1}\right)$ & $\tilde{\theta}_{2}\left(=\bar{\theta}+\rho \tilde{\epsilon}_{1}+\tilde{\epsilon}_{2}\right)$ \\
$r_{t-1, t}$ & - & $\left(1+\rho^{E}\right) \tilde{\epsilon}_{1}+(1+\omega) \tilde{s}+\tilde{e}$ & $-\left[\left(\rho^{E}-\rho\right) \tilde{\epsilon}_{1}+\omega \tilde{s}+\tilde{e}\right]+\tilde{u}$ \\
\hline
\end{tabular}

Also:

- $\tilde{\epsilon}_{2}=\tilde{s}+\tilde{u}$, where $\tilde{u} \perp\left\{\tilde{s}, \tilde{\epsilon}_{1}\right\}$

- $\bar{\theta} \sim \mathcal{N}\left(\theta_{0}, \sigma^{2}(\bar{\theta})\right)$

- $\tilde{\epsilon}_{1} \sim \mathcal{N}\left(0, \sigma_{1}^{2}\right), \tilde{\epsilon}_{2} \sim \mathcal{N}\left(0, \sigma_{2}^{2}\right), \tilde{s} \sim \mathcal{N}\left(0, \sigma_{s}^{2}\right), \tilde{e} \sim \mathcal{N}\left(0, \sigma_{e}^{2}\right)$

\section{Expectations of Future Cash Flows:}

1. At $t=0$ the expected cash flows at dates 1 and 2 are $E_{0}\left[\tilde{\theta}_{1}\right]=E_{0}\left[\tilde{\theta}_{2}\right]=\bar{\theta}$ respectively. ${ }^{33}$

2. The unexpected cash flow at time 1 is $\tilde{\epsilon}_{1}$, so the total realized time 1 cash flow is $\tilde{\theta}_{1}=\bar{\theta}_{1}+\tilde{\epsilon}_{1}$.

3. At $t=1$, the conditional expected value of the time 2 cash flow reflects both accounting and non-accounting information. We assume a linear relation between the time 1 and time 2 accounting growth. Specifically $E^{R}\left[\tilde{\theta}_{2} \mid \tilde{\theta}_{1}\right]=\bar{\theta}_{2}+\rho \tilde{\epsilon}_{1}$, where $\rho$ is a measure of the accounting growth persistence. ${ }^{34}$ The $R$ superscript denotes Rational. Since investors are not necessarily rational in this setting, their perceived expectations may not be rational.

4. The investor also observes non-accounting based information. We summarize this information as the signal $\tilde{s}=E^{R}\left[\tilde{\theta}_{2} \mid \Omega_{1}\right]-E^{R}\left[\tilde{\theta}_{2} \mid \tilde{\theta}_{1}\right]$, where $\Omega_{1}$ denotes the set of all information available to the investor at time 1 . $\tilde{s}$ would represent the total effect of non-accounting based information on the price, were investors rational. Note that by definition $s$ is orthogonal to accounting-based information - it can be thought of as summarizing the residual from the projection of $\Omega_{1}$ onto $\theta_{1}$.

Market Price Reactions to Information: Since investors are risk neutral and fully rational, conditional expected price changes equal zero, and the price at time $1\left(P_{1}\right)$ is

\footnotetext{
${ }^{33}$ This assumption makes $(B-M)_{0}$ a perfect proxy for $E_{0}\left[r_{0,1}^{B}\right]$. If this were not the case, the model results would be qualitatively the same, but algebraically more complicated.

${ }^{34}$ In our empirical tests, the implicit specification will be different: there we assume a linear relation between the log-book return and future returns.
} 
equal to $E^{R}\left[B_{2} \mid \Omega_{1}\right]$. However, as discussed earlier, in this model there are three possible biases in the way investors set prices:

1. We model over and underreaction to tangible information by allowing investors to believe that the persistence in cash flow growth is greater than it really is (i.e., they think it is $\rho^{E}$ when it is really $\left.\rho<\rho^{E}\right)$. Investors then set prices according to this belief.

2. We model investor over and underreaction to intangible information by allowing the price response to the time 1 intangible information to be $(1+\omega) \tilde{s}$ rather than $s . \omega$ is thus the fractional overreaction to intangible information; if investors are rational, $\omega=0$. Consistent with DHS, $\omega>0$ could result from the investor overconfidence about their ability to interpret vague information, and $\omega<0$ (underreaction to intangible information) could result from underconfidence.

3. In the model the time 1 price deviates from the expected payoff by $\tilde{e} \sim \mathcal{N}\left(0, \sigma_{e}^{2}\right)$, where $\tilde{e}$ is pure noise (i.e., is orthogonal to $\theta_{2}, \tilde{\epsilon}_{1}$ and $\tilde{s}$ ). One can interpret this "noise" term as an extreme form of overreaction where investors can receive a signal with zero precision, and act as though the signal is informative. However, as mentioned earlier, other interpretations are possible. ${ }^{35}$

As a result of these three biases, the time 1 price is not the expected payoff $\left(P_{1} \neq\right.$ $E_{t}^{R}\left[\tilde{B}_{2}\right]$ ), so price changes (returns) are predictable using both past returns and tangible information. In the next subsection we consider the return patterns these three biases will generate, and ask how we can empirically separate these effects.

\section{B.2. Regression Estimates}

This subsection motivates the regressions we use to evaluate the importance of extrapolation bias, overreaction, and noise on stock returns. We consider both univariate and multivariate regressions of future price changes on past price changes, book value changes and book-to-market ratios. We carry out the related regressions in Section IV. The derivations of the mathematical results in this Section are given in Appendix C.

\section{Return Reversal:}

Consider first a univariate regression of future price changes $r_{1,2}\left(\equiv P_{2}-P_{1}\right)$ on past price changes $r_{0,1}$. This is equivalent to the long-horizon regression used by DeBondt and Thaler (1985). Based on our model assumptions, this coefficient is:

$$
\beta=-\left(\frac{\left(\rho^{E}-\rho\right)\left(1+\rho^{E}\right) \sigma_{1}^{2}+\omega(1+\omega) \sigma_{s}^{2}+\sigma_{e}^{2}}{\left(1+\rho^{E}\right)^{2} \sigma_{1}^{2}+(1+\omega)^{2} \sigma_{s}^{2}+\sigma_{e}^{2}}\right)
$$

If investors are fully rational $\left(\rho^{E}=\rho, \omega=0\right.$, and $\left.\sigma_{e}^{2}=0\right), \beta$ will be zero. However, a negative coefficient will result when investors over-extrapolate earnings $\left(\rho^{E}>\rho\right)$, overreact to intangible information $(\omega>0)$, incorporate noise into the price $\left(\sigma_{e}^{2}>0\right)$, or any combination of these three.

\footnotetext{
${ }^{35}$ For example, prices can fall if investors receive liquidity shocks that force them to sell.
} 


\section{Isolating the Extrapolation Effect:}

The extrapolation effect can be directly estimated with the following univariate regression of $r_{1,2}$ on the lagged book return $\left(r_{0,1}^{B} \equiv B_{1}-B_{0}\right)$.

$$
r_{1,2}=\alpha+\beta_{B} r_{0,1}^{B}+\epsilon
$$

The estimated coefficient from this regression will equal,

$$
\beta_{B}=-\left(\rho^{E}-\rho\right)\left(\frac{\sigma_{1}^{2}}{\sigma^{2}(\bar{\theta})+\sigma_{1}^{2}}\right) .
$$

This will be negative if $\rho^{E}>\rho$ (when the investor over-extrapolates past earnings growth) and will be zero if investors properly assess tangible information (if $\rho^{E}=\rho$ ). Neither overreaction to growth $(\omega)$ nor noise $\left(\sigma_{e}^{2}\right)$ affects $\beta_{B}$, so $\beta_{B}$ isolates the extrapolation effect.

Intuitively, this regression works because $r^{B}$ is a proxy for the time 1 unexpected cash flow. However $r^{B}$ is a noisy proxy because it is the sum of the expected and unexpected cash flows. We can better isolate the unexpected cash flows by controlling for the expected component of $r^{B}$. We can do this by including the lagged book-to-market ratio on the RHS of this regression:

$$
r_{1,2}=\alpha+\beta_{B} r_{0,1}^{B}+\beta_{B M}(B-M)_{0}+\epsilon
$$

By controlling for the lagged book-to-market ratio, we control for the component of the book return that is expected and increase the absolute value of the coefficient of $r^{B}$. The coefficients from this multivariate regression are:

$$
\begin{aligned}
\beta_{B} & =-\left(\rho^{E}-\rho\right) \\
\beta_{B M} & =\beta_{B} / 2
\end{aligned}
$$

Thus, the regression on past book return isolates the extrapolation effect. We can isolate the overreaction and noise effects by using a multivariate regression of $r_{1,2}$ on past return, past book return and the lagged book-to-market ratio:

$$
r_{1,2}=\alpha+\beta_{B M}(B-M)_{0}+\beta_{B} r_{0,1}^{B}+\beta_{R} r_{0,1}+\tilde{\epsilon}
$$

The coefficients in this regression are:

$$
\begin{aligned}
\beta_{R} & =-\left(\frac{\sigma_{e}^{2}+\omega(1+\omega) \sigma_{s}^{2}}{\sigma_{e}^{2}+(1+\omega)^{2} \sigma_{s}^{2}}\right) \\
\beta_{B} & =-\beta_{R}\left(1+\rho^{E}\right)-\left(\rho^{E}-\rho\right) \\
\beta_{B M} & =\beta_{B} / 2
\end{aligned}
$$

The "intangible reversal" coefficient in this regression, $\beta_{R}$, is indicative of the effect of past returns on future returns, after controlling for the tangible information in the book return $\left(r_{0,1}^{B}\right)$. From equation (15), this will be negative when there is either noise 
or overreaction to intangible information. However, because of the presence of the controls, the magnitude of this coefficient is unaffected by under or overreaction to tangible information. Equation (15) shows that:

1. If $\sigma_{e}^{2} \gg \sigma_{s}^{2}, \beta_{R} \rightarrow-1$.

This coefficient captures the intangible return reversal. If all of the return between $t=0$ and $t=1$ that is not related to the book returns is due to pure noise, then this return must completely reverse on average.

2. If $\sigma_{e}^{2}>0$, but $\omega=0$, the $\beta_{R} \rightarrow-\sigma_{e}^{2} /\left(\sigma_{e}^{2}+\sigma_{s}^{2}\right)$ implying that $-1<\beta_{R}<0$.

The past return will contain information about future growth, but will also contain noise. This will mean that there will be incomplete reversal.

3. If $\sigma_{e}^{2}=0$, but $\omega>0$, then $\beta_{R}=-\omega /(1+\omega)$, again implying that $-1<\beta_{R}<0$.

The intuition for this coefficient is straightforward: the time 1 price change is $(1+$ $\omega) \tilde{s}$, of which $-\omega s$ is reversed at time 2 . This means that a fraction $\omega /(1+\omega)$ of this component of the price move is eventually reversed. Again with these parameters, there is incomplete reversal.

Interestingly, results 2 and 3 indicate that it is impossible to distinguish between the case of pure noise $\left(\sigma_{e}^{2}>0, \omega=0\right)$ and overreaction $\left(\omega>0, \sigma_{e}^{2}=0\right)$. This makes intuitive sense: the econometrician cannot directly observe $s_{g}$, but can only infer it through price movements. What this means is that, based on the analysis here, we will be unable to discriminate between overreaction and pure noise. ${ }^{36}$ As we will discuss later, it is only possible to discriminate between these two alternatives by finding better proxies for the information about future cash flows, and analyzing whether the changes in mispricing are related to the arrival of this information.

It is important to note that, unlike in the univariate regression (11), the coefficient $\beta_{B}$ in this multivariate regression will not necessarily be zero if there is no extrapolation bias (if $\rho^{E}=\rho$ ), because it is a control for the tangible component of the past returns. Similarly, the lagged book-to-market ratio $(B-M)_{0}$ in this regression serves as a control for the ex-ante forecastable component of the book return (the $\bar{\theta}_{1}$ term in $r^{B}$ ). Since, in the models, $(B-M)_{0}=-2 \bar{\theta}, \beta_{B M}=\beta_{B} / 2$.

\section{B.3. Direct Intangible Return Estimation}

An alternative way to generate the results described in the last subsection is to first isolate the intangible return by regressing $\tilde{r}_{0,1}$ on $r_{0,1}^{B}$ and $(B-M)_{0}$ :

$$
r_{0,1}=\gamma_{0}+\gamma_{B M}(B-M)_{0}+\gamma_{B} r_{0,1}^{B}+\tilde{v}
$$

The residual from this regression, the component of the past return that is orthogonal to the unexpected book return, is defined as the intangible return (though it captures both

\footnotetext{
${ }^{36}$ Similarly, it is impossible to distinguish between overreaction and noise by looking at the relation between past return and book return and future book return.
} 
the return associated with intangibles and the noise term):

$$
r_{I}^{(B)}(0,1) \equiv \tilde{v} \equiv\left(r_{1,2}-\gamma_{0}-\gamma_{B M}(B-M)_{0}-\gamma_{B} r_{0,1}^{B}\right)=(1+\omega) \tilde{s}+\tilde{e}
$$

The $(B)$ superscript denotes that this return is orthogonalized with respect to the unexpected book return. Then, a modified version of the regression in equation (14) (the only change being the substitution of $r_{0,1}^{I}$ for $r_{0,1}:$ )

$$
r_{1,2}=\alpha+\beta_{B M}^{\prime}(B-M)_{0}+\beta_{B}^{\prime} r_{0,1}^{B}+\beta_{I}^{\prime} r_{I}^{(B)}(0,1)+\tilde{\epsilon}
$$

yields the regression coefficients:

$$
\begin{aligned}
\beta_{I}^{\prime} & =-\left(\frac{\sigma_{e}^{2}+\omega(1+\omega) \sigma_{s}^{2}}{\sigma_{e}^{2}+(1+\omega)^{2} \sigma_{s}^{2}}\right) \\
\beta_{B}^{\prime} & =-\left(\rho^{E}-\rho\right) \\
\beta_{B M}^{\prime} & =\beta_{B}^{\prime} / 2
\end{aligned}
$$

Notice that the coefficient $\beta_{I}^{\prime}$ is identical to that in equation (15), and $\beta_{B}^{\prime}$ and $\beta_{B M}^{\prime}$ are identical to those in equation (13). Thus, the coefficients in this regression tell us directly about the magnitude of the noise/intangible effect $\left(\beta_{I}^{\prime}\right)$ and the extrapolation effect $\left(\beta_{B}^{\prime}\right)$.

One final item of note here: in this model, if there is only overreaction to intangible information or noise, but no overreaction to tangible information, and if $\rho \approx 1$, then the two coefficients $\gamma_{B M}$ and $\gamma_{B}$ in the regression in equation (14) will be $-\beta_{R} / 2,-\beta_{R}$, and $\beta_{R}$, respectively. In this case, some straightforward algebra shows that the best estimate of $r_{1,2}$ is (a constant times) $\left((B-M)_{1}-\frac{(B-M)_{0}}{2}\right)$, in other words close to the book-to-market ratio at time 1 . What this illustrates is that, depending on some of the persistence parameters, the current book-to-market ratio may end up being a good proxy for the intangible information, and specifically a much better proxy than the past return itself, which incorporates the effects of both tangible and intangible information.

\section{Derivation of Model Equations}

\section{Derivation of Equation (10):}

The univariate regression coefficient in equation (10) is equal to:

$$
\beta=\frac{\operatorname{cov}\left(r_{1,2}, r_{0,1}\right)}{\operatorname{var}\left(r_{0,1}\right)}
$$

¿From the equations for $r_{0,1}$ and $r_{1,2}$ in Table 1 , and given that that $\epsilon_{1}, \tilde{s}, \tilde{e}$, and $\tilde{u}$ are mutually uncorrelated, and that $\epsilon_{1} \sim \mathcal{N}\left(0, \sigma^{1}\right), s \sim \mathcal{N}\left(0, \sigma_{s}^{2}\right), e \sim \mathcal{N}\left(0, \sigma_{e}^{2}\right)$ this is equal to:

$$
\beta=\frac{\operatorname{cov}\left(r_{1,2}, r_{0,1}\right)}{\operatorname{var}\left(r_{0,1}\right)}=\frac{-\left(\rho^{E}-\rho\right)\left(1+\rho^{E}\right) \sigma_{1}^{2}-\omega(1+\omega) \sigma_{s}^{2}-\sigma_{e}^{2}}{\left(1+\rho^{E}\right)^{2} \sigma_{1}^{2}+(1+\omega)^{2} \sigma_{s}^{2}+\sigma_{e}^{2}}
$$




\section{Derivation of Equation (12):}

From the equations for $r_{1,2}$ and $r_{1,2}^{B}$ given in Table 1, and given the assumption that $\tilde{\epsilon}_{1}$ and $\bar{\theta}_{1}$ are uncorrelated, the regression coefficient is equal to:

$$
\beta_{B}=\frac{\operatorname{cov}\left(r_{1,2}, r_{0,1}^{B}\right)}{\operatorname{var}\left(r_{0,1}^{B}\right)}=\frac{-\left(\rho^{E}-\rho\right) \sigma_{1}^{2}}{\sigma^{2}(\bar{\theta})+\sigma_{1}^{2}}=-\left(\rho^{E}-\rho\right)\left(\frac{\sigma_{1}^{2}}{\sigma^{2}(\bar{\theta})+\sigma_{1}^{2}}\right) .
$$

\section{Derivation of Equation (13):}

Define: $X=\left[\begin{array}{c}r_{0,1}^{B} \\ (B-M)_{0}\end{array}\right]$, then using the equations for $r_{0,1}^{B}$ and $(B-M)_{0}$ in Table 1, we have that:

$$
\operatorname{var}(X)=\left[\begin{array}{cc}
\sigma^{2}(\bar{\theta})+\sigma_{1}^{2} & -2 \sigma^{2}(\bar{\theta}) \\
-2 \sigma^{2}(\bar{\theta}) & 4 \sigma^{2}(\bar{\theta})
\end{array}\right]
$$

and

$$
\operatorname{var}(X)^{-1}=\frac{1}{\sigma_{1}^{2}}\left[\begin{array}{cc}
1 & 1 / 2 \\
1 / 2 & \left(1+\sigma_{1}^{2} / \sigma^{2}(\bar{\theta})\right) / 4
\end{array}\right]
$$

From the equations for $r_{0,1}^{B}, r_{1,2}$ and $(B-M)_{0}$ in Table 1 , we have that

$$
\operatorname{cov}\left(X, r_{1,2}\right)=\left[\begin{array}{c}
-\left(\rho^{E}-\rho\right) \sigma_{1}^{2} \\
0
\end{array}\right]
$$

giving the vector of regression coefficients as:

$$
\left[\begin{array}{c}
\beta_{B} \\
\beta_{B M}
\end{array}\right]=\operatorname{var}(X)^{-1} \cdot \operatorname{cov}\left(X, r_{1,2}\right)=\left[\begin{array}{c}
-\left(\rho^{E}-\rho\right) \\
-\left(\rho^{E}-\rho\right) / 2
\end{array}\right]
$$

\section{Derivation of Equations (15)-(17):}

First, note that $\operatorname{cov}\left(B-M_{0}, r_{0,1}^{B}\right)=-2 \sigma^{2}(\bar{\theta})$, and $\operatorname{cov}\left(B-M_{0}, r_{0,1}\right)=\operatorname{cov}\left(B-M_{0}, r_{1,2}\right)=$ 0 . Therefore, in this regression, as in the regression discussed immediately above, $B-M_{0}$ will serve as a perfect control for the component of $r_{0,1}^{B}$ that is uncorrelated with $r_{1,2}$ and $r_{0,1}$ (i.e., for $\bar{\theta}$ ).

This means that $\beta_{B M}=\beta_{B} / 2$. It also means that the coefficients $\beta_{I R}$ and $\beta_{B}$ are identical to what they would be in the regression:

$$
r_{1,2}=\alpha+\beta_{B} \underbrace{\left(r_{0,1}^{B}+(1 / 2)(B-M)_{0}\right)}_{=\tilde{\epsilon}_{1}}+\beta_{I R} r_{0,1}+\epsilon
$$

Now, define:

$$
X=\left[\begin{array}{c}
r_{0,1}^{B}-(1 / 2)(B-M)_{0} \\
r_{1,2}
\end{array}\right] .
$$

Then:

$$
\operatorname{var}(X)=\left[\begin{array}{cc}
\sigma_{1}^{2} & \left(1+\rho^{E}\right) \sigma_{1}^{2} \\
\left(1+\rho^{E}\right) \sigma_{1}^{2} & \left(1+\rho^{E}\right)^{2} \sigma_{1}^{2}+(1+\omega)^{2} \sigma_{s}^{2}+\sigma_{e}^{2}
\end{array}\right]
$$




$$
\operatorname{cov}\left(X, r_{1,2}\right)=\left[\begin{array}{c}
-\left(\rho^{E}-\rho\right) \sigma_{1}^{2} \\
-\left(1+\rho^{E}\right)\left(\rho^{E}-\rho\right) \sigma_{1}^{2}-(1+\omega) \omega \sigma_{s}^{2}-\sigma_{e}^{2}
\end{array}\right]
$$

The inverse of the covariance matrix is:

$$
\operatorname{var}(X)^{-1}=\frac{1}{\sigma_{1}^{2}\left((1+\omega)^{2} \sigma_{s}^{2}+\sigma_{e}^{2}\right)}\left[\begin{array}{cc}
\left(1+\rho^{E}\right)^{2} \sigma_{1}^{2}+(1+\omega)^{2} \sigma_{s}^{2}+\sigma_{e}^{2} & -\left(1+\rho^{E}\right) \sigma_{1}^{2} \\
-\left(1+\rho^{E}\right) \sigma_{1}^{2} & \sigma_{1}^{2}
\end{array}\right] .
$$

giving the regression coefficients:

$$
\begin{aligned}
{\left[\begin{array}{c}
\beta_{B} \\
\beta_{I R}
\end{array}\right] } & =\operatorname{var}(X)^{-1} \cdot \operatorname{cov}\left(X, r_{1,2}\right) \\
& =\frac{1}{(1+\omega)^{2} \sigma_{s}^{2}+\sigma_{e}^{2}}\left[\begin{array}{c}
\left(1+\rho^{E}\right)\left(\omega(1+\omega) \sigma_{s}^{2}+\sigma_{e}^{2}\right)-\left(\rho^{E}-\rho\right)\left((1+\omega)^{2} \sigma_{s}^{2}+\sigma_{e}^{2}\right) \\
-\omega(1+\omega) \sigma_{s}^{2}-\sigma_{e}^{2}
\end{array}\right],
\end{aligned}
$$

or, simplifying,

$$
\begin{aligned}
\beta_{I R} & =-\left(\frac{\sigma_{e}^{2}+\omega(1+\omega) \sigma_{s}^{2}}{\sigma_{e}^{2}+(1+\omega)^{2} \sigma_{s}^{2}}\right) \\
\beta_{B} & =-\beta_{I R}\left(1+\rho^{E}\right)-\left(\rho^{E}-\rho\right) .
\end{aligned}
$$


Table 2: Average Correlation Coefficients of Book-to-Market and Past Return Measures

This table reports the average annual cross-sectional correlation coefficients (in \%) for a set of variables for the period 1968-2001. The standard errors for these correlation coefficients are calculated using a Newey-West procedure with 6 lags, using the time-series of the correlation coefficients. t-statistics in parentheses

\begin{tabular}{|c||ccccc|}
\hline & $b m_{t}$ & $b m_{t-5}$ & $r_{B}(t-5, t)$ & $r(t-5, t)$ & $\boldsymbol{\iota}(t-5, t)$ \\
\hline \hline$b m_{t}$ & 100.0 & 52.7 & -10.4 & -47.8 & 18.9 \\
& & $(6.07)$ & $(-0.44)$ & $(-3.66)$ & $(1.47)$ \\
\hline$b m_{t-5}$ & & 100.0 & -44.0 & 19.1 & 13.8 \\
& & & $(-7.79)$ & $(1.05)$ & $(1.22)$ \\
\hline$r_{B}(t-5, t)$ & & & 100.0 & 41.5 & 2.2 \\
& & & & $(4.86)$ & $(0.18)$ \\
\hline$r(t-5, t)$ & & & & 100.0 & -1.9 \\
& & & & & $(-0.08)$ \\
\hline$\iota(t-5, t)$ & & & & & 100.0 \\
& & & & & \\
\hline
\end{tabular}

\section{Table 3: Fama-MacBeth Regressions of Monthly Returns on Book-to-Market and Past Return Measures}

1968:07-2001:12, All Months, t-statistics in parentheses

This table reports the results of a set of Fama-MacBeth regressions of future returns on fundamental-price ratios, past accounting-growth measures, and past returns. $b m_{t}, b m_{t-5}$ and $r^{B}(t-5, t)$ are, respectively, the log book-to-market ratios at times $t$ and $t-5$, the $\log$ book return from $t-5$ to $t . r(t-5,5)$ is the past 5 -year log return, lagged 6 months, and $\boldsymbol{\iota}(t-5,5)$ is the composite log share issuance over the same period. More details on the construction of these variables are given in Section A. All coefficients are $X 100$.

\begin{tabular}{|c||cccccc|}
\hline & Const & $b m_{t}$ & $b m_{t-5}$ & $r_{B}(t-5, t)$ & $r(t-5, t)$ & $\iota(t-5, t)$ \\
\hline \hline 1 & 1.274 & 0.296 & & & & \\
& $(5.01)$ & $(3.44)$ & & & & \\
2 & 1.204 & & 0.115 & & & \\
& $(4.68)$ & & $(1.82)$ & & & \\
3 & 1.268 & & & -0.117 & & \\
& $(4.79)$ & & & $(-1.87)$ & & \\
4 & 1.303 & & & & -0.237 & \\
& $(5.18)$ & & & & $(-3.08)$ & \\
5 & 1.190 & & & & & \\
& $(4.44)$ & & & & & \\
6 & 1.206 & & 0.097 & -0.061 & & \\
& $(4.64)$ & & $(1.37)$ & $(-0.90)$ & & \\
7 & 1.263 & & 0.232 & 0.229 & -0.344 & \\
& $(5.19)$ & & $(2.64)$ & $(2.60)$ & $(-3.45)$ & \\
8 & 1.241 & & 0.173 & 0.170 & -0.300 & -0.519 \\
& $(5.02)$ & & $(2.10)$ & $(2.00)$ & $(-3.14)$ & $(-4.07)$ \\
\hline
\end{tabular}




\title{
Table 4: Fama-MacBeth Regressions with Intangible Returns
}

\author{
1968:07-2001:12, t-statistics in parentheses
}

This table reports the results of a set of Fama-MacBeth regressions of returns on past returns, accountinggrowth measures and intangible returns. Calculation of the intangible returns are described in the text. $r^{I(B)}$ denotes the log intangible return (relative to the book return) from $t-5$ to $t ; b m_{t-5}$ and $r_{B}(t-5, t)$ are, respectively, the log book-to-market ratio at time $t-5$, and the $\log$ book return from $t-5$ to $t$. The variables used in sales, cash-flow, and earnings regressions are defined similarly. The final regression uses the total tangible return, as described in the text. The average $R^{2}$ s reported are for the cross-sectional regressions of past returns on past accounting-growth measures. All coefficients are $X 100$.

\begin{tabular}{|c|c|c|c|c|c|c|c|}
\hline & Const & $b m_{t}$ & $b m_{t-5}$ & $r_{B}(t-5, t)$ & $r^{I(B)}$ & $r(t-5, t)$ & $R_{a v g}^{2}$ \\
\hline 1 & 1.206 & & "0.097 & -0.062 & & \multirow{6}{*}{$\begin{array}{l}-0.344 \\
(-3.45)\end{array}$} & \multirow{6}{*}{$36.63 \%$} \\
\hline & $(4.64)$ & & $(1.37)$ & $(-0.92)$ & & & \\
\hline 2 & 1.264 & & 0.232 & 0.228 & & & \\
\hline & $(5.19)$ & & $(2.64)$ & $(2.58)$ & & & \\
\hline \multirow[t]{3}{*}{3} & 1.206 & & 0.097 & -0.062 & -0.344 & & \\
\hline & $(4.64)$ & & $(1.37)$ & $(-0.92)$ & $(-3.45)$ & & \\
\hline & Const & $s p_{t}$ & $s p_{t-5}$ & $r_{S}(t-5, t)$ & $r^{I(S)}$ & $r(t-5, t)$ & $R_{\text {avg }}^{2}$ \\
\hline 4 & $\begin{array}{l}1.060 \\
(4.07)\end{array}$ & $\begin{array}{l}0.194 \\
(3.41)\end{array}$ & & & & \multirow{5}{*}{$\begin{array}{l}-0.333 \\
(-3.85)\end{array}$} & \\
\hline 5 & 1.072 & & 0.145 & 0.289 & & & \\
\hline & $(4.32)$ & & $(2.66)$ & $(4.66)$ & & & \\
\hline \multirow[t]{3}{*}{6} & 1.041 & & 0.084 & 0.105 & -0.333 & & $21.32 \%$ \\
\hline & $(3.93)$ & & (1.67) & $(1.92)$ & $(-3.85)$ & & \\
\hline & Const & $c p_{t}$ & $c p_{t-5}$ & $r_{C}(t-5, t)$ & $r^{I(C)}$ & $r(t-5, t)$ & $R_{\text {avg }}^{2}$ \\
\hline 7 & $\begin{array}{l}1.919 \\
(7.44)\end{array}$ & $\begin{array}{l}0.323 \\
(4.21)\end{array}$ & & & & \multirow{5}{*}{$\begin{array}{l}-0.479 \\
(-4.36)\end{array}$} & \multirow{5}{*}{$47.03 \%$} \\
\hline 8 & 1.923 & & 0.289 & 0.242 & & & \\
\hline & $(7.73)$ & & $(3.41)$ & $(3.95)$ & & & \\
\hline \multirow[t]{3}{*}{9} & 1.348 & & 0.073 & -0.049 & -0.479 & & \\
\hline & $(5.42)$ & & $(1.05)$ & $(-1.11)$ & $(-4.36)$ & & \\
\hline & Const & $e p_{t}$ & $e p_{t-5}$ & $r_{E}(t-5, t)$ & $r^{I(E)}$ & $\bar{r} r(t-5, t)$ & $R_{\text {avg }}^{2}$ \\
\hline 10 & $\begin{array}{l}1.923 \\
(7.41)\end{array}$ & $\begin{array}{l}0.275 \\
(3.81)\end{array}$ & & & & \multirow{5}{*}{$\begin{array}{l}-0.454 \\
(-4.10)\end{array}$} & \\
\hline 11 & 1.928 & & 0.251 & 0.233 & & & \\
\hline & $(7.53)$ & & $(3.00)$ & $(4.14)$ & & & \\
\hline \multirow[t]{3}{*}{12} & 1.323 & & 0.064 & -0.003 & -0.454 & & $45.58 \%$ \\
\hline & $(5.37)$ & & $(0.97)$ & $(-0.09)$ & $(-4.10)$ & & \\
\hline & Const & & \multicolumn{2}{|c|}{$r^{T(T o t)}(t-5, t)$} & $r^{I(T o t)}$ & & $\overline{R_{\text {avg }}^{2}}$ \\
\hline 13 & $\begin{array}{l}1.278 \\
(5.21)\end{array}$ & & \multicolumn{2}{|c|}{$\begin{array}{l}-0.102 \\
(-1.43)\end{array}$} & $\begin{array}{l}-0.459 \\
(-3.96)\end{array}$ & & $58.46 \%$ \\
\hline
\end{tabular}




\section{Table 5: Fama-MacBeth Regressions of Returns on Lagged Growth Measures 1968:07-2001:12, t-statistics in parentheses}

The results presented in this Table are almost identical to those in shown in Table 4, except that here we break down the past-5-year book return, sales-return, cash-flow-return, and earnings-return into $t-5$ to $t-3$ and $t-3$ to $t$ values. $r^{T\left(B^{*}\right)}$ and $r^{I\left(B^{*}\right)}$ denote, respectively, the tangible and intangible return calculated relative to lagged book-to-price ratio and the two book return measures. All coefficients are $X 100$, and Fama-MacBeth t-statistics are in parentheses.

The average $R^{2}$ s reported are for the cross-sectional regressions of past returns on past accounting-growth measures.

\begin{tabular}{|c|c|c|c|c|c|c|c|c|}
\hline & Const & $b m_{t-5}$ & $r_{B}(t-5, t-3)$ & $r_{B}(t-3, t)$ & $r(t-5, t)$ & $r^{I\left(B^{*}\right)}$ & $r^{T\left(B^{*}\right)}$ & $R_{a v g}^{2}$ \\
\hline 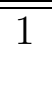 & $\begin{array}{l}1.269 \\
(5.21)\end{array}$ & $\begin{array}{l}0.224 \\
(2.53)\end{array}$ & $\begin{array}{l}0.225 \\
(2.40)\end{array}$ & $\begin{array}{l}0.223 \\
(2.01)\end{array}$ & $\begin{array}{l}-0.344 \\
(-3.38)\end{array}$ & & & \\
\hline 2 & $\begin{array}{l}1.218 \\
(4.69)\end{array}$ & $\begin{array}{l}0.097 \\
(1.35)\end{array}$ & $\begin{array}{l}0.018 \\
(0.22)\end{array}$ & $\begin{array}{l}-0.133 \\
(-1.58)\end{array}$ & & $\begin{array}{l}-0.344 \\
(-3.38)\end{array}$ & & \\
\hline 3 & $\begin{array}{l}1.205 \\
(4.55)\end{array}$ & & & & & $\begin{array}{l}-0.344 \\
(-3.38)\end{array}$ & $\begin{array}{l}-0.073 \\
(-0.91)\end{array}$ & $38.79 \%$ \\
\hline 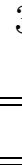 & Const & $s p_{t-5}$ & $r_{S}(t-5, t-3)$ & $r_{S}(t-3, t)$ & $r(t-5, t)$ & $r^{I\left(S^{*}\right)}$ & $r^{T\left(S^{*}\right)}$ & $R_{\text {avg }}^{2}$ \\
\hline 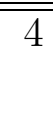 & $\begin{array}{l}1.082 \\
(4.39)\end{array}$ & $\begin{array}{l}0.142 \\
(2.63)\end{array}$ & $\begin{array}{l}0.272 \\
(3.87)\end{array}$ & $\begin{array}{l}0.304 \\
(3.83)\end{array}$ & $\begin{array}{l}-0.337 \\
(-3.87)\end{array}$ & & & \\
\hline 5 & $\begin{array}{l}1.050 \\
(3.99)\end{array}$ & $\begin{array}{l}0.082 \\
(1.65)\end{array}$ & $\begin{array}{l}0.154 \\
(2.22)\end{array}$ & $\begin{array}{l}0.070 \\
(0.99)\end{array}$ & & $\begin{array}{l}-0.337 \\
(-3.87)\end{array}$ & & \\
\hline \multirow[t]{2}{*}{6} & $\begin{array}{l}0.993 \\
(3.72)\end{array}$ & & & & & $\begin{array}{l}-0.337 \\
(-3.87)\end{array}$ & $\begin{array}{l}0.219 \\
(1.87)\end{array}$ & $22.42 \%$ \\
\hline & Const & $c p_{t-5}$ & $r_{C}(t-5, t-3)$ & $r_{C}(t-3, t)$ & $\overline{c r(t-5, t)}$ & $r^{I\left(C^{*}\right)}$ & 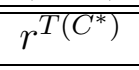 & $R_{\text {avg }}^{2}$ \\
\hline 7 & $\begin{array}{l}1.927 \\
(7.56)\end{array}$ & $\begin{array}{l}0.299 \\
(3.29)\end{array}$ & $\begin{array}{l}0.303 \\
(4.04)\end{array}$ & $\begin{array}{l}0.239 \\
(3.97)\end{array}$ & $\begin{array}{l}-0.478 \\
(-4.22)\end{array}$ & & & \\
\hline 8 & $\begin{array}{l}1.342 \\
(5.39)\end{array}$ & $\begin{array}{l}0.068 \\
(0.95)\end{array}$ & $\begin{array}{l}-0.036 \\
(-0.65)\end{array}$ & $\begin{array}{l}-0.042 \\
(-0.88)\end{array}$ & & $\begin{array}{l}-0.478 \\
(-4.22)\end{array}$ & & \\
\hline \multirow[t]{2}{*}{9} & $\begin{array}{l}1.200 \\
(4.77)\end{array}$ & & & & & $\begin{array}{l}-0.478 \\
(-4.22)\end{array}$ & $\begin{array}{l}-0.023 \\
(-0.33)\end{array}$ & $48.36 \%$ \\
\hline & Const & $e p_{t-5}$ & $r_{E}(t-5, t-3)$ & $r_{E}(t-3, t)$ & $r(t-5, t)$ & $r^{I\left(E^{*}\right)}$ & $r^{T} r^{T\left(E^{*}\right)}$ & $R_{\text {avg }}^{2}$ \\
\hline 10 & $\begin{array}{l}1.936 \\
(7.20)\end{array}$ & $\begin{array}{l}0.263 \\
(2.85)\end{array}$ & $\begin{array}{l}0.297 \\
(4.16)\end{array}$ & $\begin{array}{l}0.209 \\
(3.82)\end{array}$ & $\begin{array}{l}-0.452 \\
(-3.90)\end{array}$ & & & \\
\hline 11 & $\begin{array}{l}1.313 \\
(5.25)\end{array}$ & $\begin{array}{c}0.057 \\
(0.83)\end{array}$ & $\begin{array}{l}0.007 \\
(0.16)\end{array}$ & $\begin{array}{l}-0.015 \\
(-0.36)\end{array}$ & & $\begin{array}{l}-0.452 \\
(-3.90)\end{array}$ & & \\
\hline 12 & $\begin{array}{l}1.189 \\
(4.74)\end{array}$ & & & & & $\begin{array}{l}-0.452 \\
(-3.90) \\
\end{array}$ & $\begin{array}{c}0.008 \\
(0.12)\end{array}$ & $47.58 \%$ \\
\hline
\end{tabular}


Table 6: Fama-MacBeth Regressions of Returns on Fundamental-Price Ratios, Lagged Returns and Lagged Growth Measures

1968:07-2001:12, January Only, Coefficients $\times 100$, t-statistics in parentheses

\begin{tabular}{|c|c|c|c|c|c|c|}
\hline & Const & $b m_{t}$ & $b m_{t-5}$ & $r_{B}(t-5, t)$ & $r^{I(B)}$ & $r(t-5, t)$ \\
\hline $\mathrm{A}$ & $\begin{array}{l}4.641 \\
(4.47)\end{array}$ & & & & & $\begin{array}{l}-1.784 \\
(-4.16)\end{array}$ \\
\hline 1 & $\begin{array}{l}4.314 \\
(3.84)\end{array}$ & $\begin{array}{l}1.628 \\
(3.61)\end{array}$ & & & & \\
\hline 2 & $\begin{array}{l}4.410 \\
(4.56)\end{array}$ & & $\begin{array}{l}0.833 \\
(2.03)\end{array}$ & $\begin{array}{l}0.943 \\
(2.24)\end{array}$ & & $\begin{array}{l}-2.259 \\
(-4.09)\end{array}$ \\
\hline 3 & $\begin{array}{l}4.717 \\
(3.99) \\
\end{array}$ & & $\begin{array}{l}-0.149 \\
(-0.46) \\
\end{array}$ & $\begin{array}{l}-1.043 \\
(-3.79) \\
\end{array}$ & $\begin{array}{l}-2.259 \\
(-4.09) \\
\end{array}$ & \\
\hline & Const & $s p_{t}$ & $s p_{t-5}$ & $r_{S}(t-5, t)$ & $r^{I(S)}$ & $r(t-5, t)$ \\
\hline 1 & $\begin{array}{l}3.410 \\
(3.18)\end{array}$ & $\begin{array}{l}1.155 \\
(3.75)\end{array}$ & & & & \\
\hline 2 & $\begin{array}{l}4.156 \\
(4.25)\end{array}$ & & $\begin{array}{l}0.671 \\
(2.74)\end{array}$ & $\begin{array}{l}0.661 \\
(1.98)\end{array}$ & & $\begin{array}{l}-2.156 \\
(-4.51)\end{array}$ \\
\hline 3 & $\begin{array}{l}4.647 \\
(3.87) \\
\end{array}$ & & $\begin{array}{l}0.320 \\
(1.47) \\
\end{array}$ & $\begin{array}{l}-0.587 \\
(-2.38) \\
\end{array}$ & $\begin{array}{l}-2.156 \\
(-4.51) \\
\end{array}$ & \\
\hline & Const & $c p_{t}$ & $c p_{t-5}$ & ${ }^{r_{C}(t-5, t)}$ & $r^{I(C)}$ & $\overline{c r(t-5, t)}$ \\
\hline 1 & $\begin{array}{l}5.162 \\
(3.35)\end{array}$ & $\begin{array}{l}0.752 \\
(1.96)\end{array}$ & & & & \\
\hline 2 & $\begin{array}{l}4.533 \\
(4.04)\end{array}$ & & $\begin{array}{l}0.213 \\
(0.62)\end{array}$ & $\begin{array}{l}0.181 \\
(0.69)\end{array}$ & & $\begin{array}{l}-1.950 \\
(-3.34)\end{array}$ \\
\hline 3 & $\begin{array}{l}2.620 \\
(2.57) \\
\end{array}$ & & $\begin{array}{l}-0.808 \\
(-2.49) \\
\end{array}$ & $\begin{array}{l}-1.125 \\
(-4.38) \\
\end{array}$ & $\begin{array}{l}-1.950 \\
(-3.34) \\
\end{array}$ & \\
\hline & Const & $e p_{t}$ & $e p_{t-5}$ & $r_{E}(t-5, t)$ & $r^{I(E)}$ & $r(t-5, t)$ \\
\hline 1 & $\begin{array}{l}5.117 \\
(3.35)\end{array}$ & $\begin{array}{l}0.641 \\
(1.86)\end{array}$ & & & & \\
\hline 2 & $\begin{array}{l}4.507 \\
(3.92)\end{array}$ & & $\begin{array}{l}0.219 \\
(0.73)\end{array}$ & $\begin{array}{l}0.275 \\
(1.21)\end{array}$ & & $\begin{array}{l}-1.934 \\
(-3.34)\end{array}$ \\
\hline 3 & $\begin{array}{l}2.326 \\
(2.22) \\
\end{array}$ & & $\begin{array}{l}-0.717 \\
(-2.64) \\
\end{array}$ & $\begin{array}{l}-0.822 \\
(-3.92) \\
\end{array}$ & $\begin{array}{l}-1.934 \\
(-3.34) \\
\end{array}$ & \\
\hline & "Const & & \multicolumn{2}{|c|}{$\overline{r^{T(T o t)}(t-5, t)}$} & $r^{I(T o t)}$ & \\
\hline & $\begin{array}{l}3.697 \\
(3.49)\end{array}$ & & \multicolumn{2}{|c|}{$\begin{array}{l}-1.289 \\
(-3.41)\end{array}$} & $\begin{array}{l}-2.619 \\
(-4.52)\end{array}$ & \\
\hline
\end{tabular}


Table 7: Fama-MacBeth Regressions of Returns on Fundamental-Price Ratios, Lagged Returns and Lagged Growth Measures

1968:07-2001:12, February-December Only, Coefficients $\times 100$, t-statistics in parentheses

\begin{tabular}{|c|c|c|c|c|c|c|}
\hline & Const & $b m_{t}$ & $b m_{t-5}$ & $r_{B}(t-5, t)$ & $r^{I(B)}$ & $r(t-5, t)$ \\
\hline $\mathrm{A}$ & $\begin{array}{l}0.962 \\
(3.66)\end{array}$ & & & & & $\begin{array}{l}-0.073 \\
(-1.03)\end{array}$ \\
\hline 1 & $\begin{array}{l}0.955 \\
(3.59)\end{array}$ & $\begin{array}{l}0.155 \\
(1.96)\end{array}$ & & & & \\
\hline 2 & $\begin{array}{l}0.939 \\
(3.63)\end{array}$ & & $\begin{array}{l}0.165 \\
(2.02)\end{array}$ & $\begin{array}{l}0.139 \\
(1.58)\end{array}$ & & $\begin{array}{l}-0.142 \\
(-1.54)\end{array}$ \\
\hline 3 & $\begin{array}{l}0.860 \\
(3.19) \\
\end{array}$ & & $\begin{array}{r}0.110 \\
(1.69) \\
\end{array}$ & $\begin{array}{r}0.020 \\
(0.29) \\
\end{array}$ & $\begin{array}{l}-0.142 \\
(-1.54) \\
\end{array}$ & \\
\hline & Const & $s p_{t}$ & $s p_{t-5}$ & $r_{S}(t-5, t)$ & $r^{I(S)}$ & $r(t-5, t)$ \\
\hline 1 & $\begin{array}{l}0.817 \\
(2.96)\end{array}$ & $\begin{array}{l}0.096 \\
(1.93)\end{array}$ & & & & \\
\hline 2 & $\begin{array}{l}0.773 \\
(2.96)\end{array}$ & & $\begin{array}{c}0.093 \\
(1.88)\end{array}$ & $\begin{array}{l}0.216 \\
(3.64)\end{array}$ & & $\begin{array}{l}-0.147 \\
(-1.85)\end{array}$ \\
\hline 3 & $\begin{array}{l}0.708 \\
(2.61) \\
\end{array}$ & & $\begin{array}{r}0.056 \\
(1.22) \\
\end{array}$ & $\begin{array}{r}0.132 \\
(2.40) \\
\end{array}$ & $\begin{array}{l}-0.147 \\
(-1.85) \\
\end{array}$ & \\
\hline & Const & $c p_{t}$ & $c p_{t-5}$ & 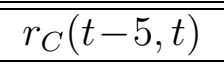 & $r^{I(C)}$ & $r(t-5, t)$ \\
\hline 1 & $\begin{array}{l}1.538 \\
(6.21)\end{array}$ & $\begin{array}{l}0.262 \\
(3.45)\end{array}$ & & & & \\
\hline 2 & $\begin{array}{l}1.655 \\
(6.61)\end{array}$ & & $\begin{array}{l}0.296 \\
(3.48)\end{array}$ & $\begin{array}{l}0.220 \\
(3.47)\end{array}$ & & $\begin{array}{l}-0.319 \\
(-2.98)\end{array}$ \\
\hline 3 & $\begin{array}{l}1.212 \\
(4.62) \\
\end{array}$ & & $\begin{array}{r}0.153 \\
(2.30) \\
\end{array}$ & $\begin{array}{r}0.033 \\
(0.83) \\
\end{array}$ & $\begin{array}{l}-0.319 \\
(-2.98) \\
\end{array}$ & \\
\hline & Const & $e p_{t}$ & $e p_{t-5}$ & $r_{E}(t-5, t)$ & $r^{I(E)}$ & $r(t-5, t)$ \\
\hline 1 & $\begin{array}{l}1.553 \\
(6.26)\end{array}$ & $\begin{array}{c}0.224 \\
(3.10)\end{array}$ & & & & \\
\hline 2 & $\begin{array}{l}1.649 \\
(6.50)\end{array}$ & & $\begin{array}{l}0.250 \\
(2.92)\end{array}$ & $\begin{array}{l}0.212 \\
(3.60)\end{array}$ & & $\begin{array}{l}-0.298 \\
(-2.75)\end{array}$ \\
\hline 3 & $\begin{array}{l}1.199 \\
(4.65) \\
\end{array}$ & & $\begin{array}{r}0.131 \\
(2.02) \\
\end{array}$ & $\begin{array}{l}0.061 \\
(1.75) \\
\end{array}$ & $\begin{array}{l}-0.298 \\
(-2.75) \\
\end{array}$ & \\
\hline & Const & \multicolumn{3}{|c|}{ 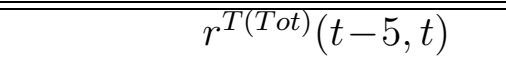 } & $r^{I(T o t)}$ & \\
\hline & $\begin{array}{l}1.045 \\
(4.07)\end{array}$ & & \multicolumn{2}{|c|}{$\begin{array}{c}-0.0175 \\
(-0.26)\end{array}$} & $\begin{array}{l}-0.309 \\
(-2.73)\end{array}$ & \\
\hline
\end{tabular}


Table 8: Annual Fama-MacBeth Regressions of $\iota(t, t+1)$ on Tangible and Intangible Return Measures

\author{
1968-2001 Fama-MacBeth t-statistics in parentheses
}

This table presents the results of a set of Fama-MacBeth regressions of our composite-issuance measure over the period 1968-2001. The dependent variable in each regression is the is the composite issuance measure $\boldsymbol{\iota}(t, t+1)$. The independent variables are the fundamental-to-price ratios, measures of fundamental performance, the intangible return from $t-5$ to $t$, and composite issuance from $t-5$ to $t$. All coefficient are $\times 100$.

\begin{tabular}{|c|c|c|c|c|c|c|}
\hline Const & $b m_{t}$ & $b m_{t-5}$ & $r^{B}(t-5, t)$ & $r^{I(B)}$ & $r(t-5, t)$ & $\boldsymbol{\iota}(t-5, t)$ \\
\hline $\begin{array}{l}-1.276 \\
(-5.64)\end{array}$ & $\begin{array}{c}-1.904 \\
(-12.74)\end{array}$ & & & & & \\
\hline $\begin{array}{l}-0.281 \\
(-0.80)\end{array}$ & & $\begin{array}{l}-0.922 \\
(-7.23)\end{array}$ & $\begin{array}{l}-1.159 \\
(-6.76)\end{array}$ & & & \\
\hline $\begin{array}{l}-1.073 \\
(-3.58)\end{array}$ & & & & & $\begin{array}{l}0.781 \\
(3.52)\end{array}$ & \\
\hline $\begin{array}{l}-0.904 \\
(-3.46)\end{array}$ & & $\begin{array}{c}-1.843 \\
(-17.29)\end{array}$ & $\begin{array}{c}-2.892 \\
(-14.01)\end{array}$ & & $\begin{array}{l}2.106 \\
(8.28)\end{array}$ & \\
\hline $\begin{array}{l}-0.281 \\
(-0.80)\end{array}$ & & $\begin{array}{l}-0.922 \\
(-7.23)\end{array}$ & $\begin{array}{l}-1.159 \\
(-6.76)\end{array}$ & $\begin{array}{l}2.106 \\
(8.28)\end{array}$ & & \\
\hline $\begin{array}{l}-0.433 \\
(-1.64)\end{array}$ & & & & & & $\begin{array}{c}7.276 \\
(18.94)\end{array}$ \\
\hline $\begin{array}{l}-0.261 \\
(-0.81)\end{array}$ & & $\begin{array}{l}-0.427 \\
(-3.58)\end{array}$ & $\begin{array}{l}-0.756 \\
(-4.45)\end{array}$ & $\begin{array}{l}1.613 \\
(7.99)\end{array}$ & & $\begin{array}{c}6.591 \\
(21.61)\end{array}$ \\
\hline
\end{tabular}


Table 9: Fama-MacBeth Regressions of Monthly Returns on Past Tangible and Intangible Returns and Composite Issuance.

1968:07-2001:12, Coefficients $\times 100$, t-statistics in parentheses

\begin{tabular}{|c|c|c|c|c|c|c|}
\hline & Const & & & & & $\iota(t-5, t)$ \\
\hline \multirow[t]{2}{*}{$\overline{\mathrm{A}}$} & $\begin{array}{l}1.189 \\
(4.44)\end{array}$ & & & & & $\begin{array}{l}-0.651 \\
(-4.28)\end{array}$ \\
\hline & Const & $\overline{l b m}_{t}$ & $\overline{l b m_{t-5}}$ & $r_{B}(t-5, t)$ & $r^{r^{I(B)}}$ & $\bar{\iota} \iota(t-5, t)$ \\
\hline 1 & $\begin{array}{l}1.243 \\
(4.80)\end{array}$ & $\begin{array}{l}0.243 \\
(2.94)\end{array}$ & & & & $\begin{array}{l}-0.518 \\
(-3.66)\end{array}$ \\
\hline 2 & $\begin{array}{l}1.200 \\
(4.59)\end{array}$ & & $\begin{array}{l}0.052 \\
(0.80)\end{array}$ & $\begin{array}{l}-0.086 \\
(-1.32)\end{array}$ & & $\begin{array}{l}-0.616 \\
(-4.34)\end{array}$ \\
\hline \multirow[t]{2}{*}{3} & $\begin{array}{l}1.202 \\
(4.60) \\
\end{array}$ & & $\begin{array}{l}0.057 \\
(0.87) \\
\end{array}$ & $\begin{array}{l}-0.083 \\
(-1.27)\end{array}$ & $\begin{array}{l}-0.300 \\
(-3.14)\end{array}$ & $\begin{array}{l}-0.519 \\
(-4.07)\end{array}$ \\
\hline & Const & $s p_{t}$ & $s p_{t-5}$ & $r_{S}(t-5, t)$ & $r^{I(S)}$ & $\boldsymbol{\iota} \boldsymbol{\iota}(t-5, t)$ \\
\hline 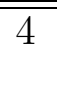 & $\begin{array}{l}1.067 \\
(4.10)\end{array}$ & $\begin{array}{l}0.168 \\
(3.07)\end{array}$ & & & & $\begin{array}{l}-0.543 \\
(-3.77)\end{array}$ \\
\hline 5 & $\begin{array}{l}1.077 \\
(4.17)\end{array}$ & & $\begin{array}{l}0.067 \\
(1.41)\end{array}$ & $\begin{array}{l}0.057 \\
(1.04)\end{array}$ & & $\begin{array}{l}-0.584 \\
(-3.97)\end{array}$ \\
\hline \multirow[t]{2}{*}{6} & $\begin{array}{l}1.074 \\
(4.15) \\
\end{array}$ & & $\begin{array}{l}0.068 \\
(1.44) \\
\end{array}$ & $\begin{array}{l}0.061 \\
(1.13) \\
\end{array}$ & $\begin{array}{l}-0.300 \\
(-3.62) \\
\end{array}$ & $\begin{array}{l}-0.511 \\
(-3.80) \\
\end{array}$ \\
\hline & Const & $c p_{t}$ & $c p_{t-5}$ & $r_{C}(t-5, t)$ & $r^{I(C)}$ & $\boldsymbol{\iota} \boldsymbol{\iota}(t-5, t)$ \\
\hline 7 & $\begin{array}{l}1.792 \\
(6.60)\end{array}$ & $\begin{array}{l}0.274 \\
(3.78)\end{array}$ & & & & $\begin{array}{l}-0.481 \\
(-3.53)\end{array}$ \\
\hline 8 & $\begin{array}{l}1.271 \\
(4.92)\end{array}$ & & $\begin{array}{l}0.043 \\
(0.68)\end{array}$ & $\begin{array}{l}-0.051 \\
(-1.19)\end{array}$ & & $\begin{array}{l}-0.579 \\
(-4.22)\end{array}$ \\
\hline \multirow[t]{2}{*}{9} & $\begin{array}{l}1.286 \\
(5.01) \\
\end{array}$ & & $\begin{array}{l}0.048 \\
(0.75) \\
\end{array}$ & $\begin{array}{l}-0.052 \\
(-1.20)\end{array}$ & $\begin{array}{l}-0.426 \\
(-4.05)\end{array}$ & $\begin{array}{l}-0.457 \\
(-3.78)\end{array}$ \\
\hline & Const & $e p_{t}$ & $e p_{t-5}$ & $r_{E}(t-5, t)$ & $r^{I(E)}$ & $\boldsymbol{\iota} \iota(t-5, t)$ \\
\hline 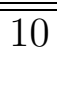 & $\begin{array}{l}1.790 \\
(6.59)\end{array}$ & $\begin{array}{l}0.231 \\
(3.40)\end{array}$ & & & & $\begin{array}{l}-0.477 \\
(-3.53)\end{array}$ \\
\hline 11 & $\begin{array}{l}1.233 \\
(4.78)\end{array}$ & & $\begin{array}{l}0.032 \\
(0.54)\end{array}$ & $\begin{array}{l}-0.006 \\
(-0.16)\end{array}$ & & $\begin{array}{l}-0.562 \\
(-4.10)\end{array}$ \\
\hline 12 & $\begin{array}{l}1.250 \\
(4.88) \\
\end{array}$ & & $\begin{array}{l}0.037 \\
(0.62) \\
\end{array}$ & $\begin{array}{l}-0.007 \\
(-0.18)\end{array}$ & $\begin{array}{l}-0.403 \\
(-3.81)\end{array}$ & $\begin{array}{l}-0.451 \\
(-3.79)\end{array}$ \\
\hline
\end{tabular}


Table 10: Fama-MacBeth Regressions of Monthly Returns on Cashflow to Price and Past Sales Growth Measures

1968:07-2001:12, All Months, t-statistics in parentheses

This Table we perform Fama-MacBeth regressions of future returns on the cashflow-to-price ratio $c p_{t}$, the log total sales growth $g_{S L S}$, the $\log$ sales-return $r_{S L S}$, and our share issuance measure $\iota$. Panel A gives the results for the full sample of firms; the regressions in Panel B are run after excluding, each year, the $10 \%$ of the firms with the largest $\boldsymbol{\iota}(t-\tau, t)$. All coefficients are $\times 100$.

\begin{tabular}{|c|c|c|c|c|c|}
\hline \multicolumn{6}{|c|}{ Panel A: Full Sample Results } \\
\hline & Const & $c p_{t}$ & $g_{S L S}(t-5, t)$ & $r_{S L S}(t-5, t)$ & $\boldsymbol{\iota}(t-5, t)$ \\
\hline 1 & $\begin{array}{l}1.919 \\
(7.44)\end{array}$ & $\begin{array}{l}0.323 \\
(4.21)\end{array}$ & & & \\
\hline 2 & $\begin{array}{l}1.366 \\
(5.70)\end{array}$ & & $\begin{array}{l}-0.234 \\
(-3.17)\end{array}$ & & \\
\hline 3 & $\begin{array}{l}2.029 \\
(8.00)\end{array}$ & $\begin{array}{l}0.315 \\
(4.23)\end{array}$ & $\begin{array}{l}-0.214 \\
(-3.05)\end{array}$ & & \\
\hline 4 & $\begin{array}{l}1.255 \\
(4.87)\end{array}$ & & & $\begin{array}{l}-0.043 \\
(-0.73)\end{array}$ & \\
\hline 5 & $\begin{array}{l}1.205 \\
(4.59)\end{array}$ & & & & $\begin{array}{l}-0.607 \\
(-4.14)\end{array}$ \\
\hline 6 & $\begin{array}{l}1.791 \\
(6.59)\end{array}$ & $\begin{array}{l}0.274 \\
(3.78)\end{array}$ & & & $\begin{array}{l}-0.481 \\
(-3.53)\end{array}$ \\
\hline 7 & $\begin{array}{l}1.256 \\
(4.88)\end{array}$ & & $\begin{array}{l}-0.076 \\
(-1.23)\end{array}$ & & $\begin{array}{l}-0.547 \\
(-4.03)\end{array}$ \\
\hline 8 & $\begin{array}{l}1.863 \\
(6.82)\end{array}$ & $\begin{array}{l}0.277 \\
(3.83)\end{array}$ & $\begin{array}{l}-0.095 \\
(-1.54)\end{array}$ & & $\begin{array}{l}-0.403 \\
(-3.19)\end{array}$ \\
\hline 9 & $\begin{array}{l}1.256 \\
(4.88)\end{array}$ & & & $\begin{array}{l}-0.076 \\
(-1.23)\end{array}$ & $\begin{array}{l}-0.623 \\
(-4.15)\end{array}$ \\
\hline 10 & $\begin{array}{l}1.863 \\
(6.82)\end{array}$ & $\begin{array}{l}0.277 \\
(3.83)\end{array}$ & & $\begin{array}{l}-0.095 \\
(-1.54)\end{array}$ & $\begin{array}{l}-0.498 \\
(-3.58)\end{array}$ \\
\hline \multicolumn{6}{|c|}{ Panel B: $10 \%$ Truncated Sample Results } \\
\hline & Const & $c p_{t}$ & $g_{S L S}(t-5, t)$ & $r_{S L S}(t-5, t)$ & $\iota(t-5, t)$ \\
\hline 12 & $\begin{array}{l}1.887 \\
(7.35)\end{array}$ & $\begin{array}{l}0.291 \\
(3.83)\end{array}$ & & & \\
\hline 13 & $\begin{array}{l}1.342 \\
(5.62)\end{array}$ & & $\begin{array}{l}-0.123 \\
(-1.59)\end{array}$ & & \\
\hline 14 & $\begin{array}{l}1.951 \\
(7.64)\end{array}$ & $\begin{array}{l}0.292 \\
(3.92)\end{array}$ & $\begin{array}{l}-0.116 \\
(-1.57)\end{array}$ & & \\
\hline 15 & $\begin{array}{l}1.208 \\
(4.50)\end{array}$ & & & & $\begin{array}{l}-0.605 \\
(-2.68)\end{array}$ \\
\hline 16 & $\begin{array}{l}1.234 \\
(4.68)\end{array}$ & & $\begin{array}{l}-0.038 \\
(-0.57)\end{array}$ & & $\begin{array}{l}-0.575 \\
(-2.72)\end{array}$ \\
\hline 17 & $\begin{array}{l}1.828 \\
(6.46)\end{array}$ & $\begin{array}{l}0.266 \\
(3.69)\end{array}$ & $\begin{array}{l}-0.063 \\
(-0.95)\end{array}$ & & $\begin{array}{l}-0.343 \\
(-1.74)\end{array}$ \\
\hline
\end{tabular}


Table 11: Fama-MacBeth Regressions of Market Betas on Tangible and Intangible Return Measures

Annual, 1968-1999, Newey-West t-statistics in parentheses

This table reports the results the coefficients and t-statistics from of a set of Fama and MacBeth (1973) regressions. The dependent variable in each cross-sectional regression is $\hat{\beta}(t, t+2)$, the estimated slope coefficient from a regression of the excess return of the individual stock's excess return on the CRSP value-weighted portfolio excess return from July of year $t$ through June of year $t+2$. The independent variables in these regressions are the lagged estimated market beta, $\hat{\beta}_{t-5}$, estimated using returns from July: $(t-6)$ through June: $(t-4) ; b m_{t}$, the book-to-market ratio as of the end of December: $(t-1) ; b m_{t-5}$, the book-to-market ratio as of the end of December: $(t-6)$; and $r_{B V}(t-5, t), r^{T(B)}(t-5, t), r^{I(B)}(t-5, t)$, the book-return, and the tangible and intangible returns using book, calculated as described in the text. Measures using Sales, Cashflow, and Earnings are calculated similarly. We perform annual cross-sectional regressions from $t=1968$ through 1999. Standard errors are calculated using a Newey-West procedure with 11 lags.

\begin{tabular}{|c|c|c|c|c|c|c|c|}
\hline & Const & $\hat{\beta}_{t-5}$ & $b m_{t}$ & $b m_{t-5}$ & $r_{B V}(t-5, t)$ & $r^{T(B)}(t-5, t)$ & $r^{I(B)}(t-5, t)$ \\
\hline 1 & $\begin{array}{c}0.828 \\
(32.01)\end{array}$ & $\begin{array}{c}0.281 \\
(11.92)\end{array}$ & $\begin{array}{l}-0.081 \\
(-2.62)\end{array}$ & & & & \\
\hline 2 & $\begin{array}{c}0.866 \\
(22.03)\end{array}$ & $\begin{array}{c}0.276 \\
(12.22)\end{array}$ & & $\begin{array}{l}-0.071 \\
(-2.48)\end{array}$ & $\begin{array}{l}-0.056 \\
(-2.78)\end{array}$ & & \\
\hline \multirow[t]{2}{*}{3} & $\begin{array}{c}0.907 \\
(22.23)\end{array}$ & $\begin{array}{c}0.266 \\
(12.16)\end{array}$ & & & & $\begin{array}{l}-0.084 \\
(-2.69)\end{array}$ & $\begin{array}{l}0.061 \\
(1.90)\end{array}$ \\
\hline & Const & $\hat{\beta}_{t-5}$ & $s p_{t}$ & $s p_{t-5}$ & $r_{S L S}(t-5, t)$ & $r^{T(S)}(t-5, t)$ & $r^{I(S)}(t-5, t)$ \\
\hline 4 & $\begin{array}{c}0.858 \\
(32.37)\end{array}$ & $\begin{array}{c}0.280 \\
(13.51)\end{array}$ & $\begin{array}{l}0.031 \\
(1.31)\end{array}$ & & & & \\
\hline 5 & $\begin{array}{c}0.852 \\
(17.55)\end{array}$ & $\begin{array}{c}0.280 \\
(13.28)\end{array}$ & & $\begin{array}{c}0.032 \\
(1.28)\end{array}$ & $\begin{array}{l}0.022 \\
(0.72)\end{array}$ & & \\
\hline \multirow[t]{2}{*}{6} & $\begin{array}{c}0.824 \\
(26.00) \\
\end{array}$ & $\begin{array}{c}0.263 \\
(12.71)\end{array}$ & & & & $\begin{array}{l}0.092 \\
(3.20) \\
\end{array}$ & $\begin{array}{l}-0.015 \\
(-0.63)\end{array}$ \\
\hline & Const & $\hat{\beta}_{t-5}$ & $c p_{t}$ & $c p_{t-5}$ & $r_{C F}(t-5, t)$ & $r^{T(C)}(t-5, t)$ & $r^{I(C)}(t-5, t)$ \\
\hline 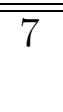 & $\begin{array}{c}0.593 \\
(28.05)\end{array}$ & $\begin{array}{c}0.298 \\
(12.95)\end{array}$ & $\begin{array}{l}-0.101 \\
(-9.25)\end{array}$ & & & & \\
\hline 8 & $\begin{array}{c}0.680 \\
(10.91)\end{array}$ & $\begin{array}{c}0.290 \\
(13.52)\end{array}$ & & $\begin{array}{l}-0.060 \\
(-2.68)\end{array}$ & $\begin{array}{l}-0.018 \\
(-0.81)\end{array}$ & & \\
\hline \multirow[t]{2}{*}{9} & $\begin{array}{c}0.826 \\
(23.75)\end{array}$ & $\begin{array}{c}0.279 \\
(11.81)\end{array}$ & & & & $\begin{array}{l}-0.042 \\
(-1.40)\end{array}$ & $\begin{array}{l}0.102 \\
(4.25) \\
\end{array}$ \\
\hline & Const & $\hat{\beta}_{t-5}$ & $e p_{t}$ & $e p_{t-5}$ & $r_{E R N}(t-5, t)$ & $r^{T(E)}(t-5, t)$ & $r^{I(E)}(t-5, t)$ \\
\hline 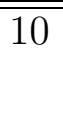 & $\begin{array}{c}0.553 \\
(13.80)\end{array}$ & $\begin{array}{c}0.302 \\
(13.10)\end{array}$ & $\begin{array}{l}-0.102 \\
(-3.83)\end{array}$ & & & & \\
\hline 11 & $\begin{array}{c}0.638 \\
(18.04)\end{array}$ & $\begin{array}{c}0.296 \\
(14.04)\end{array}$ & & $\begin{array}{l}-0.065 \\
(-4.84)\end{array}$ & $\begin{array}{l}-0.014 \\
(-0.62)\end{array}$ & & \\
\hline 12 & $\begin{array}{c}0.819 \\
(24.04)\end{array}$ & $\begin{array}{c}0.281 \\
(11.67)\end{array}$ & & & & $\begin{array}{l}-0.044 \\
(-1.23)\end{array}$ & $\begin{array}{l}0.112 \\
(3.83) \\
\end{array}$ \\
\hline & Const & $\hat{\beta}_{t-5}$ & & & & $r_{T}^{(T o t)}(t-5, t)$ & $r^{I(T o t)}(t-5, t)$ \\
\hline $\begin{array}{l}13 \\
14\end{array}$ & $\begin{array}{c}0.772 \\
(31.24) \\
1.112 \\
(22.68)\end{array}$ & $\begin{array}{c}0.285 \\
(12.08)\end{array}$ & & & & $\begin{array}{l}0.010 \\
(0.40) \\
0.018 \\
(0.92) \\
\end{array}$ & $\begin{array}{l}0.095 \\
(3.09) \\
0.110 \\
(3.14) \\
\end{array}$ \\
\hline
\end{tabular}


Table 12: Fama-MacBeth Regressions of Return Standard Deviation on Tangible and Intangible Return Measures

\author{
Annual, 1968-1999, Coefficients $\times 1000$, Newey-West t-statistics in parentheses
}

This table reports the results the coefficients $(\times 1000)$ and t-statistics from of a set of Fama and MacBeth (1973) regressions. The dependent variable in each cross-sectional regression is $\hat{\sigma}(t, t+2)$, the estimated standard deviation the excess return of the individual stock's excess return from July of year $t$ through June of year $t+2$. The independent variables in these regressions are the lagged estimated excess return standard-deviation, $\hat{\sigma}_{t-5}$, estimated using returns from July: $(t-6)$ through June: $(t-4) ; b m_{t}$, the bookto-market ratio as of the end of December: $(t-1) ; b m_{t-5}$, the book-to-market ratio as of the end of December: $(t-6)$; and $r_{B V}(t-5, t), r^{T(B)}(t-5, t), r^{I(B)}(t-5, t)$, the book-return, and the tangible and intangible returns using book, calculated as described in the text. Measures using Sales, Cashflow, and Earnings are calculated similarly. We perform annual cross-sectional regressions from $t=1968$ through 1999. Standard errors are calculated using a Newey-West procedure with 11 lags.

\begin{tabular}{|c|c|c|c|c|c|c|c|}
\hline & Const & $\hat{\sigma}_{t-5}$ & $b m_{t}$ & $b m_{t-5}$ & $r_{B V}(t-5, t)$ & $r^{T(B)}(t-5, t)$ & $r^{I(B)}(t-5, t)$ \\
\hline 1 & $\begin{array}{l}13.461 \\
(46.69)\end{array}$ & $\begin{array}{c}121.819 \\
(6.33)\end{array}$ & $\begin{array}{l}-0.712 \\
(-1.62)\end{array}$ & & & & \\
\hline 2 & $\begin{array}{l}14.218 \\
(44.66)\end{array}$ & $\begin{array}{c}116.513 \\
(6.22)\end{array}$ & & $\begin{array}{l}-0.987 \\
(-1.74)\end{array}$ & $\begin{array}{l}-1.271 \\
(-5.41)\end{array}$ & & \\
\hline \multirow[t]{2}{*}{3} & $\begin{array}{l}14.548 \\
(20.58)\end{array}$ & $\begin{array}{c}111.443 \\
(5.34)\end{array}$ & & & & $\begin{array}{l}-1.527 \\
(-2.23)\end{array}$ & $\begin{array}{l}0.402 \\
(1.68)\end{array}$ \\
\hline & Const & $\hat{\sigma}_{t-5}$ & $s p_{t}$ & $s p_{t-5}$ & $r_{S L S}(t-5, t)$ & $r^{T(S)}(t-5, t)$ & $r^{I(S)}(t-5, t)$ \\
\hline 4 & $\begin{array}{l}13.670 \\
(33.51)\end{array}$ & $\begin{array}{c}122.315 \\
(6.14)\end{array}$ & $\begin{array}{l}0.375 \\
(1.53)\end{array}$ & & & & \\
\hline 5 & $\begin{array}{l}13.848 \\
(31.39)\end{array}$ & $\begin{array}{c}119.078 \\
(6.16)\end{array}$ & & $\begin{array}{c}0.197 \\
(0.58)\end{array}$ & $\begin{array}{l}0.043 \\
(0.30)\end{array}$ & & \\
\hline \multirow[t]{2}{*}{6} & $\begin{array}{l}13.628 \\
(28.24)\end{array}$ & $\begin{array}{c}112.555 \\
(5.09)\end{array}$ & & & & $\begin{array}{l}0.303 \\
(1.05) \\
\end{array}$ & $\begin{array}{l}-0.512 \\
(-2.28)\end{array}$ \\
\hline & Const & $\hat{\sigma}_{t-5}$ & $c p_{t}$ & $c p_{t-5}$ & $r_{C F}(t-5, t)$ & $r^{T(C)}(t-5, t)$ & $r^{I(C)}(t-5, t)$ \\
\hline 7 & $\begin{array}{l}10.389 \\
(16.69)\end{array}$ & $\begin{array}{c}118.805 \\
(5.80)\end{array}$ & $\begin{array}{l}-1.304 \\
(-7.67)\end{array}$ & & & & \\
\hline 8 & $\begin{array}{l}10.971 \\
(13.21)\end{array}$ & $\begin{array}{c}116.389 \\
(5.52)\end{array}$ & & $\begin{array}{l}-1.178 \\
(-4.01)\end{array}$ & $\begin{array}{l}-0.537 \\
(-5.37)\end{array}$ & & \\
\hline 9 & $\begin{array}{l}13.897 \\
(66.30)\end{array}$ & $\begin{array}{c}109.685 \\
(4.59)\end{array}$ & & & & $\begin{array}{l}-1.167 \\
(-4.66)\end{array}$ & $\begin{array}{l}1.004 \\
(6.30) \\
\end{array}$ \\
\hline & Const & $\hat{\sigma}_{t-5}$ & $e p_{t}$ & $e p_{t-5}$ & $r_{E R N}(t-5, t)$ & $r^{T(E)}(t-5, t)$ & $r^{I(E)}(t-5, t)$ \\
\hline 10 & $\begin{array}{c}9.435 \\
(18.02)\end{array}$ & $\begin{array}{c}116.821 \\
(5.60)\end{array}$ & $\begin{array}{c}-1.454 \\
(-12.04)\end{array}$ & & & & \\
\hline 11 & $\begin{array}{c}9.784 \\
(11.07)\end{array}$ & $\begin{array}{c}115.106 \\
(5.53)\end{array}$ & & $\begin{array}{l}-1.435 \\
(-5.37)\end{array}$ & $\begin{array}{l}-0.430 \\
(-6.66)\end{array}$ & & \\
\hline 12 & $\begin{array}{l}13.901 \\
(66.52)\end{array}$ & $\begin{array}{c}108.374 \\
(4.49)\end{array}$ & & & & $\begin{array}{l}-1.270 \\
(-6.45)\end{array}$ & $\begin{array}{l}1.266 \\
(5.73)\end{array}$ \\
\hline & Const & $\hat{\sigma}_{t-5}$ & & & & $r^{T(T o t)}(t-5, t)$ & $r^{I(T o t)}(t-5, t)$ \\
\hline 13 & $\begin{array}{c}13.031 \\
(115.96) \\
14.584 \\
(31.89)\end{array}$ & $\begin{array}{c}112.655 \\
(4.48)\end{array}$ & & & & $\begin{array}{l}-0.344 \\
(-1.27) \\
-0.268 \\
(-0.87)\end{array}$ & $\begin{array}{l}0.768 \\
(4.32) \\
0.927 \\
(4.14)\end{array}$ \\
\hline
\end{tabular}




\title{
Table 13: Results from Time-Series Regressions of Value-Weighted Portfolio Returns on Sets of Factor-Mimicking Portfolios
}

\author{
1968:07-2001:12, All Months, t-statistics in parentheses
}

This table reports the results of time-series regressions of three zero-investment portfolio returns on benchmark portfolio returns. The dependent variables in Panel A, B and $\mathrm{C}$ are, respectively, the time series of value-weighted coefficients from the Fama-MacBeth cross-sectional regressions of monthly returns on $(\mathrm{A}) r^{I(B)}$ as in Table 4, regression 3; (B) $\iota(t-5, t)$ in univariate cross-sectional regressions as in Table 9 , regression $\mathrm{A}$; and $(\mathrm{C}) \iota(t-5, t)$ in univariate cross-sectional regressions with $b m_{t-5}, r^{B}(t-5, t), r^{I(B)}$ as in Table 9, regression 3. The value-weighting of the coefficients is described in Section VI.B of the text.

The independent variables in regressions 2 and 3 in each panel are the contemporaneous monthly excess market return, SMB and HML zero-investment portfolio returns, obtained from Kenneth French.

OLS t-statistics are reported in parentheses below each of the coefficients. The final column reports $R^{2} \mathrm{~S}$ (in \%) for each of the the time series regressions. All coefficients are $\times 100$.

\begin{tabular}{|c|c|c|c|c|c|}
\hline \multicolumn{6}{|c|}{ Panel A: Intangible Portfolio Return } \\
\hline & $\hat{\alpha}$ & $\hat{\beta}_{M k t}$ & $\hat{\beta}_{S M B}$ & $\hat{\beta}_{H M L}$ & $R^{2}(\%)$ \\
\hline 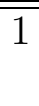 & $\begin{array}{l}-0.363 \\
(-2.04)\end{array}$ & & & & \\
\hline 2 & $\begin{array}{l}-0.440 \\
(-2.53)\end{array}$ & $\begin{array}{l}0.177 \\
(4.73)\end{array}$ & & & 5.3 \\
\hline 3 & $\begin{array}{l}0.176 \\
(1.89)\end{array}$ & $\begin{array}{l}-0.074 \\
(-3.33)\end{array}$ & $\begin{array}{c}-0.377 \\
(-13.04)\end{array}$ & $\begin{array}{l}-1.066 \\
(-32.18)\end{array}$ & 74.4 \\
\hline \multicolumn{6}{|c|}{ Panel B: Issuance Portfolio Return } \\
\hline & $\hat{\alpha}$ & $\hat{\beta}_{M k t}$ & $\hat{\beta}_{S M B}$ & $\hat{\beta}_{H M L}$ & $R^{2}(\%)$ \\
\hline 4 & $\begin{array}{l}-0.469 \\
(-3.38)\end{array}$ & & & & \\
\hline 5 & $\begin{array}{l}-0.625 \\
(-5.60) \\
\end{array}$ & $\begin{array}{c}0.357 \\
(14.91) \\
\end{array}$ & & & 35.7 \\
\hline 6 & $\begin{array}{l}-0.462 \\
(-4.71) \\
\end{array}$ & $\begin{array}{l}0.227 \\
(9.69) \\
\end{array}$ & $\begin{array}{l}0.217 \\
(7.11) \\
\end{array}$ & $\begin{array}{l}-0.275 \\
(-7.86) \\
\end{array}$ & 52.8 \\
\hline \multicolumn{6}{|c|}{ Panel $C:$} \\
\hline & $\hat{\alpha}$ & $\hat{\beta}_{M k t}$ & $\hat{\beta}_{S M B}$ & $\hat{\beta}_{H M L}$ & $R^{2}(\%)$ \\
\hline 7 & $\begin{array}{l}-0.335 \\
(-2.77)\end{array}$ & & & & \\
\hline 8 & $\begin{array}{l}-0.458 \\
(-4.45)\end{array}$ & $\begin{array}{c}0.281 \\
(12.72)\end{array}$ & & & 28.8 \\
\hline 9 & $\begin{array}{l}-0.465 \\
(-4.84)\end{array}$ & $\begin{array}{c}0.231 \\
(10.06)\end{array}$ & $\begin{array}{l}0.263 \\
(8.79)\end{array}$ & $\begin{array}{l}0.019 \\
(0.54) \\
\end{array}$ & 40.6 \\
\hline
\end{tabular}

